\title{
A gênese do sistema de Filosofia Transcendental de Schopenhauer ${ }^{1}$
}

\author{
The genesis of the system of Transcendental Philosophy of Schopenhauer
}

\author{
Alexandre Teles \\ Doutorando em Filosofia pela UFRGS \\ E-mail: selettelesa@hotmail.com
}

\begin{abstract}
Resumo: Neste artigo é apresentada a tese segundo a qual parte do projeto filosófico de Arthur Schopenhauer deve ser entendida como o estabelecimento de um sistema de filosofia transcendental, constituído de uma teoria da experiência coordenada a uma teoria geral das faculdades cognitivas e a um "primeiro princípio", que apresentamos e discutimos. Assim compreendida, a filosofia de Schopenhauer guarda uma relação peculiar de continuidade com a filosofia transcendental de Kant: herda e reformula o projeto de Karl Leonhard Reinhold, articulado em resposta aos céticos Salomon Maimon e Gottlob Ernst Schulze, edificando um sistema de filosofia transcendental que contempla as ambições fundacionistas presentes no projeto de Reinhold e críticas que esse projeto recebera.
\end{abstract}

Palavras-chave: Schopenhauer; Filosofia transcendental; Reinhold.

Abstract: In this paper is presented the thesis according to which part of Arthur Schopenhauer's philosophical project should be understood as aiming at putting forward a system of transcendental philosophy. That system comprises a theory of experience coordinated to a general theory of cognitive faculties and to a "first principle" which we present and discuss. So understood, Schopenhauer's philosophy exhibits a peculiar relationship of continuity with Kant's transcendental philosophy: it inherits and reformulates Karl Leonhard Reinhold's project as it was conceived in response to the skeptics Salomon Maimon and Gottlob Ernst Schulze, building a system of transcendental philosophy which encompasses the foundationalist ambitions of Reinhold's project and some criticisms which that project had received.

Keywords: Schopenhauer; Transcendental philosophy; Reinhold.

Schopenhauer afirma que seu sistema filosófico - exposto em $O$ mundo como vontade $e$ representação - é a expressão de um pensamento único e que suas partes mantém entre si uma relação orgânica. Tais afirmações são indícios de que a filosofia de Schopenhauer compartilha com seus contemporâneos idealistas e românticos aspirações sistêmicas. Neste artigo, nos dedicaremos à tarefa de identificar, em uma parte do sistema de Schopenhauer, resultados do que seria um retorno a uma discussão que esteve na origem do Idealismo Alemão ${ }^{2}$. Mais precisamente, trataremos de mostrar que aquilo que

\footnotetext{
${ }^{1}$ Este artigo é resultado de uma pesquisa de Mestrado que resultou na dissertação de título $O$ sistema de Filosofia Transcendental de Schopenhauer: uma interpretação e defesa, orientada pelo Prof. Dr. Paulo Francisco Estrella Faria, a quem preciso agradecer pelo estímulo a escrever este texto em especial e pelos inúmeros comentários feitos a uma versão preliminar do texto da dissertação.

${ }^{2} \mathrm{O}$ leitor perceberá que nossa análise se restringe a uma discussão que ocorreu na Alemanha entre 1790 e 1794 entre Reinhold, Schulze e Maimon. Não consideraremos aqui, portanto, outras discussões, também importantes para compreender outros aspectos da filosofia de Schopenhauer, como a protagonizada pelas críticas de Jacobi à filosofia de Kant. Deixaremos para analisar essa discussão em um trabalho futuro.
} 
encontramos no primeiro livro de $O$ mundo como vontade e representação e na dissertação sobre o Princípio de Razão Suficiente é um sistema de filosofia transcendental e que este sistema é uma reformulação da Elementarphilosophie de Reinhold.

Mais especificamente, mostraremos aqui como a teoria geral das faculdades cognitivas que compõe o sistema de filosofia transcendental de Schopenhauer pode ser entendida como o amadurecimento de um projeto latente na própria Crítica da Razão Pura (CRP). Um projeto que o próprio Kant manifestou intenção de realizar: oferecer uma definitiva teoria das faculdades cognitivas que não procedesse como uma "investigação da causa de um efeito". Considerada sob esse prisma, a teoria das faculdades de Schopenhauer é mais próxima do espírito da filosofia crítica kantiana do que a teoria das faculdades cognitivas que compõe a Elementarphilosophie de Karl Leohnard Reinhold: teoria que consiste em uma "investigação psicológica das faculdades cognitivas"’3.

Kant manifestou a intenção de oferecer uma teoria das faculdades que viesse a provar - sem deixar margem para disputas - que temos dois poderes de conhecimento, entendimento e sensibilidade, e que somente a cooperação deles resulta no conhecimento empírico. Reinhold se esforçou por realizar esse projeto em sua Elementarphilosophie e recebeu inúmeras críticas. Nós apresentaremos razões para que se compreenda a teoria das faculdades de Schopenhauer como uma reformulação do projeto de Reinhold diante das críticas que este sofrera e uma recuperação daquela sugestão de Kant de que uma teoria das faculdades não deveria ser desenvolvida através do modelo de investigação etiológica. Assim, defenderemos aqui a tese segundo a qual a teoria das faculdades de Schopenhauer é concebida através de um discurso de segunda ordem ${ }^{4}$.

Compreender a teoria das faculdades de Schopenhauer como uma realização do projeto esboçado por Kant, contemplando críticas recebidas pelo projeto de Reinhold, nos ajuda a compreender por que Schopenhauer se dá ao direito de impor sua teoria das faculdades à própria filosofia transcendental de Kant e taxar esta última de contraditória ao adotar a tese segundo a qual a faculdade discursiva de conhecimento é necessária para dar unidade às representações intuitivas e, através dessa cooperação,

\footnotetext{
${ }^{3}$ Beiser (cf. BEISER, F. The Fate of Reason: German Philosophy from Kant to Fichte, 1987, p.282-3) faz uma distinção entre discurso de primeira e segunda ordem; distinção que utilizaremos como recurso metodológico ao longo deste capítulo. Um discurso de primeira ordem sobre faculdades consiste em uma "investigação psicológica das faculdades cognitivas" enquanto um discurso de segunda ordem (Beiser não contempla a possibilidade de se fazer uma teoria das faculdades através de um discurso de segunda ordem, talvez por seu livro não contemplar a filosofia de Schopenhauer nem, com o devido detalhe, o debate de Maimon com Änesidemus, por isso adotaremos aqui a sua formulação genérica) consiste em uma "investigação de nossos juízos sintéticos a priori sobre as coisas". Discordaremos de Beiser, no entanto, no que diz respeito a teses exegéticas mais específicas, que serão expostas ao longo deste capítulo.

${ }^{4} C f$. nota anterior.
} 
explicar a possibilidade da experiência ${ }^{5}$. A idéia de impor uma teoria das faculdades à própria CRP se torna aceitável ao analisarmos o próprio texto de Kant em que ele manifesta as limitações de sua teoria das faculdades (o "lado subjetivo" de sua dedução transcendental) e sua intenção de aperfeiçoá-la. Além disso, ao nos familiarizarmos com o contexto de recepção da CRP, teremos condições de dimensionar a diferenças dos projetos de Kant e Schopenhauer para, assim, melhor compreender as críticas do último ao primeiro.

Pois a própria idéia de edificar um "sistema de filosofia transcendental” faz parte do contexto de recepção da CRP, mais precisamente: é uma herança do projeto de Reinhold de compor um sistema de filosofia primeira que viesse a oferecer fundamento a todo conhecimento humano. De modo que a composição de um sistema de filosofia transcendental é estranha à CRP; essa se restringe a realizar a tarefa de mostrar como a experiência é possível, demonstrando a validade objetiva de certo conjunto de princípios $^{6}$. Assim, se Kant tinha como principal meta realizar uma propedêutica à Metafísica (que consiste basicamente na restituição do nosso direito a ter experiência: o "lado objetivo" da dedução transcendental), Reinhold pretendia fundar um sistema completo de filosofia cuja tarefa primordial era oferecer fundamento absoluto à CRP, que provasse tudo aquilo que é suposto pela dedução transcendental ${ }^{7}$, o que inclui realizar o projeto esboçado por Kant de oferecer uma definitiva teoria das faculdades cognitivas.

Ao fim deste artigo, veremos como a teoria das faculdades de Schopenhauer pode ser concebida como uma retomada do esboço de uma teoria das faculdades traçado por Kant e ensaiado por Reinhold; retomada essa que contempla críticas endereçadas ao projeto de Reinhold, moderando as pretensões de justificação última de um sistema de filosofia transcendental ao alterar o estatuto e o conteúdo do primeiro princípio de Reinhold. E, no que diz respeito à sua teoria das faculdades cognitivas, Schopenhauer lança

\footnotetext{
${ }^{5}$ Cf. TELES, A. "Um Ensaio sobre a crítica de Schopenhauer à Doutrina das Categorias de Kant", Barbarói, n.26, 2007, p. 133-59. Neste artigo, TELES nos mostra que as críticas de Schopenhauer à Doutrina das Categorias de Kant pressupõem a verdade da teoria das faculdades cognitivas de Schopenhauer.

${ }^{6}$ Tarefa que, segundo Ameriks (2003, p. 272-4), era uma tarefa modesta em comparação com o projeto ambicioso de Reinhold que reatava com o fundacionalismo representacionalista de Descartes. O projeto modesto que Ameriks defende para Kant é um projeto "fortemente regressivo", segundo o qual Kant "simplesmente pressupõe os princípios da ciência newtoniana e meramente adiciona a isso uma descrição abstrata das faculdades envolvidas nesse conhecimento e uma explicação de como essa ciência está vinculada fundamentalmente com o idealismo transcendental" (idem., p.275). Essa interpretação de Ameriks do projeto de Kant segue a linha de seu seminal artigo de 1978, segundo o qual o argumento da Dedução Transcendental (DT) deve ser entendido regressivamente: o ponto de partida é "temos conhecimento empírico" e o ponto de chegada é que necessariamente as categorias se aplicam aos objetos da experiência.

${ }^{7}$ A dedução transcendental tem outros pressupostos muito razoáveis que devem fazer parte de qualquer disputa filosófica: definições aceitáveis por um interlocutor. No caso, são as definições de experiência e de possibilidade da experiência. Reinhold se incumbe da tarefa de mostrar que o modo como Kant entendia essas noções precisava ainda ser justificado. Adiante veremos como Reinhold se pronuncia quanto a isso.
} 
mão de um discurso de segunda ordem; o que faz de sua teoria das faculdades uma teoria mais interessante que a de Reinhold, fazendo jus ao esboço de uma teoria das faculdades oferecido por Kant: não realizar uma investigação psicológica das faculdades cognitivas em uma futura teoria das faculdades.

\subsection{O projeto de Reinhold como um aperfeiçoamento da CRP; a insuficiência da dedução subjetiva das categorias a a necessidade de uma teoria das faculdades cognitivas fundamentada em um primeiro princípio}

A motivação principal do projeto filosófico de Reinhold que, como tentaremos mostrar, pode nos ser útil para compreender a filosofia transcendental de Schopenhauer, é uma posição frente à CRP, que é melhor compreendida à vista das aspirações de Kant para aquilo que declarou ter-lhe dado maior trabalho na confecção da CRP: a dedução transcendental das categorias do entendimento.

Diese Betrachtung, die etwas tief angelegt ist, hat aber zwei Seiten. Die eine bezieht sich auf die Gegenstände des reinen Verstandes und soll die objective Gültigkeit seiner Begriffe a priori darthun und begreiflich machen; eben darum ist sie auch wesentlich zu meinen Zwecken gehörig. Die andere geht darauf aus, den reinen Verstand selbst nach seiner Möglichkeit und den Erkenntnißkräften, auf denen er selbst beruht, mithin ihn in subjectiver Beziehung //AXVII// zu betrachten; und obgleich diese Erörterung in Ansehung meines Hauptzwecks von großer Wichtigkeit ist, so gehört sie doch nicht wesentlich zu demselben, weil die Hauptfrage immer bleibt: was und wie viel kann Verstand und Vernunft, frei von aller Erfahrung, erkennen? und nicht: wie ist das Vermögen zu denken selbst möglich? Da das letztere gleichsam eine Aufsuchung der Ursache zu einer gegebenen Wirkung ist und in so fern etwas einer Hypothese Ähnliches an sich hat (ob es gleich, wie ich bei anderer Gelegenheit zeigen werde, sich in der That nicht so verhält), so scheint es, als sei hier der Fall, da ich mir die Erlaubniß nehme, zu meinen, und dem Leser also auch frei stehen müsse, anders zu meinen. In Betracht dessen muß ich dem Leser mit der Erinnerung zuvorkommen: daß, im Fall meine subjective Deduction nicht die ganze Überzeugung, die ich erwarte, bei ihm gewirkt hätte, doch die objective, um die es mir hier vornehmlich zu thun ist, ihre ganze Stärke bekomme, wozu allenfalls dasjenige, was Seite 92 bis 93 [B123 - B124] gesagt wird, allein hinreichend sein kann. ${ }^{8}$ (grifo nosso)

Esse estudo, elaborado com alguma profundidade, consta de duas partes [dois lados]. Uma reporta-se aos objetos do entendimento puro e deve expor e tornar compreensível [inteligível] o valor objetivo desses conceitos a priori e, por isso mesmo, entra essencialmente no meu desígnio. A outra diz respeito ao entendimento puro, em si mesmo, do ponto de vista da sua possibilidade e das faculdades cognitivas em que assenta: estuda-o, portanto, no aspecto subjetivo. Esta discussão, embora de grande importância para o meu fim principal, não lhe pertence essencialmente, pois a questão fundamental reside sempre em saber $\underline{o}$ que podem e até onde podem o entendimento e a razão

\footnotetext{
${ }^{8}$ KANT, I. (CRP: Axvi-xvii).
} 
conhecer, independentemente da experiência e não_como é possível a própria faculdade de pensar. Uma vez que esta última questão é, de certa maneira, a investigação da causa de um efeito dado e, nessa medida, também algo semelhante a uma hipótese (embora de fato não seja assim, como noutra ocasião mostrarei) parece ser este o caso de me permitir formular opiniões e deixar ao leitor igualmente a liberdade de emitir outras diferentes. Por isso devo pedir ao leitor para se lembrar de que, se a minha dedução subjetiva não lhe tiver criado a inteira convicção que espero, a dedução objetiva, que é a que aqui me importa principalmente, conserva [recebe] toda a sua força, bastando, de resto, para isso, o que é dito nas páginas 92 a $93^{9}$. (grifo nosso)

A DT, como podemos ver nessa passagem do prefácio da $1^{a}$ edição da CRP, tem dois lados (zwei Seite): subjetivo e objetivo. O primeiro diz respeito ao modo como nossas faculdades cognitivas operam e o segundo à inteligibilidade e demonstração da validade objetiva das categorias e à conseqüente delimitação de seu uso próprio. No que diz respeito à força probante de ambas, Kant declarou estar ciente que, necessariamente ${ }^{10}$, pareceria ao leitor que a dedução subjetiva ${ }^{11}$ não possui uma rigorosa demonstração. Ora, entendemos a dedução subjetiva, diante dessas descrições de Kant do que ela seria, como um argumento que prova que temos os poderes cognitivos supostos pela CRP: entendimento e sensibilidade; sendo que por uma o objeto é dado e por outra pensado (B74). Isto é, uma prova para uma premissa da dedução objetiva; isso explicaria por que, segundo Kant, com o resultado da dedução objetiva, a dedução subjetiva "recebe toda sua força"(Axvii).

Naquela passagem do prefácio, vemos também como Kant nos remete ao $§ 14$ como a passagem em que, segundo ele, esclareceria como se articulam as deduções subjetiva e objetiva, isto é, a relação entre a teoria das faculdades suposta pela DT e a demonstração da validade objetiva das categorias (as categorias fazem parte da teoria das faculdades suposta pela DT: são os conceitos puros do entendimento). Ao analisar o $\S 14$, vemos como esse é o lugar em que Kant apresenta o conjunto de pressuposições da DT. Entre elas está, em primeiro lugar, (i) a possibilidade de se entender a conexão sintética entre

\footnotetext{
${ }^{9}$ Optamos por apresentar o texto original em alemão para comparar com a tradução portuguesa e apontar, entre colchetes, uma tradução alternativa que nos ajudará em nossa interpretação. Os familiarizados com a língua alemã notarão que nossas propostas de tradução são literais.

${ }^{10} \mathrm{O}$ advérbio "necessariamente" é usado aqui para frisar a ocorrência do verbo "müssen" na citação acima; ocorrência perdida tanto na tradução portuguesa, como na inglesa de Norman Kemp Smith.

${ }^{11}$ HENRICH (1969) propôs uma interpretação da dedução subjetiva das categorias segundo a qual se trataria de uma parte do texto da DT da $1^{\text {a }}$ edição da CRP, exclusivamente. (HENRICH, D "The Proof-Structure of Kant's Transcendental Deduction", Review of Metaphysics, 22:4, 1969, p.644-5). Nós entendemos a dedução subjetiva não como uma parte do texto da DT, exclusivamente, mas como a tese a respeito das faculdades cognitivas que é um pressuposto de toda a CRP: temos dois poderes cognitivos, entendimento e sensibilidade, os quais devem ser entendidos como os poderes cognitivos que deverão ser supostos para a teoria da experiência que será oferecida pela Lógica Transcendental ( $C f$.CRP: B74). Esse é um pressuposto para o qual Kant não se propõe a oferecer uma prova.
} 
representações - que constituem, por definição, a experiência ${ }^{12}$ - apenas (a) nos moldes da filosofia empirista (o objeto torna a representação possível) ou (b) nos moldes da filosofia transcendental (a representação torna o objeto possível). Em seguida - no final de A92 - Kant retoma o que já havia apresentado na introdução da Lógica Transcendental (A50-52/B74-76): (ii) a tese que o nosso conhecimento possui duas fontes fundamentais de natureza distinta: sensibilidade e entendimento.

O problema da dedução subjetiva está relacionado com (ii) a tese que nosso conhecimento possui duas fontes fundamentais e, aparentemente, não podemos encontrar, em toda a CRP, uma prova adequada para essa tese. No entanto, como afirmou Kant no prefácio que citamos acima, esse modo de compreender os poderes de conhecimentos humanos é útil para "die objective Gültigkeit seiner Begriffe a priori darthun und begreiflich machen" (expor e tornar inteligível o valor objetivo desses conceitos a priori), isto é, realizar a dedução objetiva. Assim, Kant utiliza como premissa da DT a tese (ii) de que nossos poderes cognitivos são entendimento e sensibilidade e cooperam para explicar como - (i) (a) nos moldes de uma filosofia transcendental, isto é, representações como condições de possibilidade dos objetos - a experiência é possível e assim realizar o seu principal objetivo: a dedução objetiva, que contém uma resposta a Hume e uma censura aos racionalistas e escolásticos que utilizavam os conceitos puros além dos domínios da experiência possível.

Ora, mas onde Kant teria realizado a dedução subjetiva? O que poderia ser uma prova de que nossos poderes cognitivos são aqueles supostos pela CRP? Uma prova para a tese que temos entendimento e sensibilidade aparece, na $2^{\mathrm{a}}$ edição da CRP (aqui temos evidências textuais para rejeitar a tese de Henrich, segundo a qual a dedução subjetiva é uma parte do texto da DT tal como ela apareceu exclusivamente na $1^{\mathrm{a}}$ edição da CRP), em comparações de nossas faculdades cognitivas com as faculdades

\footnotetext{
${ }^{12}$ Há algo que é suposto na DT e que o é em toda CRP, a saber: uma definição de experiência. Mas isso é resultado de uma exigência metodológica: algumas definições básicas precisam ser admitidas por um filósofo e devem ser comuns à tradição com a qual ele pretende dialogar. No presente caso, a definição de experiência é o que possibilita um diálogo com Hume. Definição que poderia ser formulada da seguinte maneira: percepções ligadas necessariamente. Em diversas passagens da CRP essa definição aparece, mas precisa-se distinguir essa definição ampla, geral, que Hume aceitaria, e a explicação desta dada pela CRP: subsunção de aparências à categorias. (note-se que Schopenhauer, por exemplo, dará uma explicação distinta àquela noção básica de experiência. De acordo com sua teoria que será examinada no terceiro capítulo deste trabalho, a experiência é a síntese, através da única categoria do entendimento, das sensações dadas pelos órgãos sensíveis). Vejamos, então, uma lista de definições do termo "experiência" que podemos encontrar na CRP: "(B146-8) Experiência é conhecimento empírico e esse conhecimento é o resultado da aplicação das categorias à intuições empíricas"; "(B161) Experiência é o conhecimento através de percepções conectadas"; "(B165) Experiência é conhecimento empírico e esse nada mais é que conhecer um objeto, o que nada mais é que pensar um objeto através das categorias com intuições que correspondem a eles"; (A176/B218) Experiência é um conhecimento empírico, isto é, um conhecimento que determina um objeto através de percepções. É uma síntese de percepções, não contida nas percepções, mas ela mesma contendo em uma consciência a unidade sintética do múltiplo de percepções." Em B219 (Kant comete uma pequena falha): ele afirma que há percepções que ocorrem desordenadamente, na experiência, ora, isso não pode, pelo menos, ser o mesmo sentido de experiência como ele definiu anteriormente, isto é, na frase anteriormente citada. $C f$. (B128-B129).
} 
divinas. O nosso entendimento é concebido por oposição a um entendimento divino: um entendimento intuitivo, que cria o objeto ${ }^{13}$. $\mathrm{O}$ argumento é o seguinte:

Um entendimento divino cria seu objeto.

Nosso entendimento, o entendimento humano, não cria o seu objeto.

Mas nosso entendimento conhece objetos.

Os objetos de nosso entendimento precisam ser dados por outra faculdade: a sensibilidade.

O argumento acima é o que podemos encontrar na $2^{\text {a }}$ edição da CRP que mais se aproxima da descrição oferecida por Kant a respeito do lado subjetivo da DT: um argumento que prove uma premissa que será usada na dedução objetiva, principal meta da DT, e cujo texto seja indicativo de quais são e como operam nossas faculdades cognitivas, relevantes para a explicação de como se dá o conhecimento empírico: entendimento e sensibilidade ${ }^{14}$. Agora, é importante notar que o próprio Kant revelou estar insatisfeito com a sua dedução subjetiva, ao afirmar que se tratava de "algo semelhante a uma hipótese" (Axvii) e - em uma página anterior à nossa citação - afirmar que opiniões e hipóteses devem ser rejeitadas em um livro como a CRP (Axv). Essas afirmações nos fazem compreender por que ele tenha prometido, “em outra ocasião", tratar do assunto concernente à sua dedução subjetiva (Axvii) e nos sugerem que Kant tinha em mente desenvolver uma teoria das faculdades cognitivas mais sofisticada que viesse a justificar de maneira contundente a tese de que temos dois poderes fundamentais de conhecimento ${ }^{15}$.

Ora, isso considerado, o projeto de Karl Leohnard Reinhold de estabelecer uma teoria das faculdades ${ }^{16}$ pode ser entendido como uma tentativa de realizar esse projeto que Kant mesmo já havia esboçado e, nesse aspecto, podemos entender o projeto de Reinhold como um desenvolvimento da filosofia crítica motivado pela busca de uma demonstração rigorosa do que Kant chamou do "lado" (Seite) da dedução transcendental que "diz respeito ao entendimento puro, em si mesmo, do ponto de vista da sua

\footnotetext{
${ }^{13}$ Cf. Bxlii, B68, B71-72, B159, em todas essas passagens Kant concebe a nossa sensibilidade através de uma oposição a uma possível "intuição intelectual". Agora, um entendimento intuitivo em oposição ao nosso, encontramos em B135; passagem em que a questão é pensada da seguinte maneira: ou o entendimento é intuitivo, ou é não-intuitivo, respectivamente: ou o entendimento cria o seu objeto, ou precisa que por outra o objeto the seja dado, em uma intuição sensível; em B139 se estabelece, depois do argumento do $\S 17$ - que aqui não analisaremos qual é -, o primeiro princípio do entendimento humano, que não cria o seu próprio objeto. Em B145-146, também encontramos uma indicação de que as concepções de entendimento e sensibilidade foram determinadas através de uma oposição de um entendimento que cria o seu objeto a um que não cria, que seriam, respectivamente, o entendimento divino e o humano. Essa última passagem sugere que essa oposição é fundamental para que entendamos que nossos poderes cognitivos devem ser assim concebidos, como o faz Kant em toda a $\mathrm{CRP}$, e não de outra maneira. Importante notar ainda que essa passagem está no §21, parte do texto da DT em que a prova da primeira parte está sendo revisada.

${ }^{14}$ Cf. CRP: A50-52/B74-76, A93.

${ }^{15} C f$. CRP: B74-76.

${ }^{16}$ Sobre Reinhold e o contexto histórico em questão vide BEISER (1987), CASSIRER (1923), HOYOS (2001A), DIGIOVANNI (2000A) E HARTMANN (1960).
} 
possibilidade e das faculdades cognitivas em que assenta” (den reinen Verstand selbst nach seiner Möglichkeit und den Erkenntnißkräften), que é a „dedução subjetiva“" (subjective Deduction). (Axvi-Axvii)

Independentemente de se considerar Reinhold como um genuíno seguidor de Kant ou não ${ }^{17}$, é importante levar em conta que Reinhold foi um entusiasta da recém criada filosofia crítica, e, aliás, foi fundamental para a sua divulgação ${ }^{18}$; fazia questão de deixar claro que não era um adversário de Kant e que seu objetivo era estabelecer uma Filosofia Elementar (Elementharphilosophie) ${ }^{19}$, enquanto Kant, na $\mathrm{CRP}$, realizou uma propedêutica à Metafísica, tendo exatamente dessa forma chamado a sua obra ${ }^{20}$. O projeto de sua Filosofia Elementar se caracteriza por ser uma "ciência (Wissenschaft) dos princípios de toda filosofia (...); não apenas da Metafísica"21. Essa nova ciência tinha justamente o objetivo de complementar a tarefa realizada por Kant na CRP e, ainda, conferir a ela total poder persuasivo. Como pudemos conferir acima, o principal objetivo de Kant com a CRP era realizar a contento a sua dedução objetiva, isto é, "expor e tornar compreensível [inteligível] o valor objetivo desses conceitos a priori" (Axvi). Coisa que, no seu significado histórico, consiste em uma refutação do ceticismo de Hume ${ }^{22}$ e em uma censura da Cosmologia, Teologia e Ontologia racionalista e escolástica ${ }^{23}$. Como fora reconhecido pelo próprio Kant, essa dedução objetiva se apoiava em uma prova não convincente de quais são e como operam nossos poderes cognitivos, coisa que na recepção da CRP era alvo de adversários como Eberhard $^{24}$.

\footnotetext{
${ }^{17}$ Há autores que consideram Reinhold um deturpador da filosofia crítica e há quem veja na sua Elementharphilosophie o mais genuíno desenvolvimento do projeto crítico. AMERIKS (2003), por exemplo, considera Reinhold um deturpador da filosofia crítica, enquanto BREAZEALE (2003) o considera um genuíno representante da mesma.

${ }^{18}$ Reinhold fez um grande serviço a Kant através de um periódico trabalho de divulgação no Der Teutsche Merkur com as Briefe über Kantischen Philosophie, publicadas em formato de artigos de agosto de 1786 a setembro de 1787 e em formato de livro em 1790.

${ }^{19}$ Projeto publicado primeiramente em uma versão preliminar no Ensaio sobre a teoria da faculdade-representativa humana (1789) (Versuch über die Theorie des menschelichen Vorstellungsvermögens) e, mais tarde, em uma versão mais acabada, exposta ao modo dos geômetras, nas Contribuições para a correção dos equívocos pretéritos dos filósofos (1790, p. 3-254; 12-177) (Beyträge zur Berichtigung bisheriger Mißverständnisse der Philosophen).

${ }^{20} \mathrm{CRP}:(\mathrm{B} 25, \mathrm{~B} 869)$

${ }^{21}$ Reinhold, Beyträge zur Berichtigung bisheriger Meißverständnisse der Philosophen 1790, 278; 193

${ }^{22}$ Cf. (REINHOLD, Beyträge zur Berichtigung bisheriger Meißverständnisse der Philosophen, 1790, 70); Schopenhauer também compreendia como principal tarefa da filosofia transcendental ter oferecido uma resposta a Hume: (Vorlesungen: p.48; 166-8)

${ }^{23}$ Essa é a posição de Schopenahuer em relação à filosofia crítica de Kant. (SW, I, 570-2)

${ }^{24}$ Eberhard criou o Philosophisches Magazin (em 1789) com o intuito de defender a filosofia de Leibnz da filosofia crítica de Kant. Cf. (Reinhold, Beyträge zur Berichtigung bisheriger Meißverständnisse der Philosophen 1790, 117n.)
} 
Reinhold $^{25}$ trabalhava na defesa de Kant e a sua nova ciência, a Elementharphilosophie, foi planejada justamente para retirar da CRP qualquer tipo de hipótese. Vimos acima que a dedução objetiva tem como premissa a tese de que temos duas fontes de conhecimento que produzem representações que diferem quanto à natureza. Ora, essa é uma das teses que um adepto da tradição racionalista poderia negar, alegando que entre conceitos e intuições há apenas uma diferença de graus de clareza e distinção. Por outro lado, a dedução objetiva das categorias de Kant pressupõe ainda que a possibilidade da experiência possa ser explicada através de juízos sintéticos a priori e, no mínimo, uma noção de experiência e uma noção de possibilidade da experiência. Pode-se objetar, naturalmente, que todas essas noções não precisam ser necessariamente explicadas do modo como Kant o fez na CRP e é esse tipo de objeção à nova filosofia crítica que Reinhold pretendia responder com a sua nova ciência.

Os conceitos de possibilidade da experiência, da natureza e realidade dos juizos sintéticos a priori, que formam o fundamento, exposto na Crítica, de todo o sistema kantiano, são admitidos sem prova. Eles são apresentados em exposições incompletas e sem uma total determinação de suas características. (...) [A] realidade dos conceitos em questão (...) é pressuposta. O fundamento da Crítica só pode ser provado por ela mesma através de um círculo vicioso ${ }^{26}$.

Os conceitos de representação, de percepção sensivel (sinnliche Wahrnehmung), de objetos (der Gegenstaende), de combinação (Zusammenhang) e de necessidade são, de maneira gritante, elementos essenciais do conceito kantiano de experiência e precisam de um desenvolvimento e determinação de seu sentido; coisa que, aliás, de modo algum pode ser feita pela CRP. Pois, o conceito de experiência, na medida em que é a base do sistema de Kant, simplesmente não pode ser construído a partir desse sistema, como não pode ser explicado por ele sem circularidade ${ }^{27}$.

Reinhold se incumbe da tarefa de edificar um sistema que prove tudo o que a CRP pressupôs (sistema exposto em: Beiträge ${ }^{28}$ ) e, para isso, vê a necessidade de montar um sistema à maneira dos geômetras $^{29}$ que parte do que ele chamou de princípio da consciência (Satz des Bewußtseins), o qual articula as noções de sujeito, objeto e representação e termina com o estabelecimento de que nossas faculdades cognitivas são entendimento, sensibilidade e razão.

${ }^{25}$ Reinhold, em defesa de Kant, responde a Eberhard no Allgemein Literatur-Zeitung em junho de 1789. Cf. (Reinhold, Beyträge zur Berichtigung bisheriger Meißverständnisse der Philosophen, 1790, 117n.)

${ }^{26}$ REINHOLD, K.L. Beyträge zur Berichtigung bisheriger Meißverständnisse der Philosophen, 1790, 129-130.

${ }^{27}$ REINHOLD, K.L. Beyträge zur Berichtigung bisheriger Meißverständnisse der Philosophen, 1790, 281.

${ }^{28}$ REINHOLD, K.L. Beyträge zur Berichtigung bisheriger Meißverständnisse der Philosophen, 1790, 167-254.

${ }^{29}$ Kant, ao contrário, acreditava que o modo de exposição á maneira geométrica não era adequado para a filosofia. (A726/B754; A789/B818; A791/B819) As razões de Kant para isso, dependem fundamentalmente de como Kant entende a tarefa do filósofo em relação aos conceitos que investiga, enquanto o matemático os constrói. (A712-738/B741-766). 
Do que vimos até aqui, pudemos perceber que Reinhold e Kant tinham projetos distintos e que o projeto de Reinhold tem uma peculiar relação com a filosofia crítica de Kant, imbuído de certa leitura dessa última: o objetivo de Reinhold era garantir à filosofia crítica o estatuto de ciência evidente, suprindo uma lacuna deixada por Kant em sua filosofia crítica; Kant, por sua vez, tinha como meta - no que diz respeito ao aspecto positivo da CRP, isto é, na Analítica Transcendental - a realização de uma teoria da experiência ou filosofia transcendental, estabelecendo as condições de possibilidade da experiência nos termos da questão: como são possíveis juízos sintéticos a priori? Em sua resposta a essa questão que direciona sua Analítica Transcendental, Kant teria feito uso de noções como intuições e conceitos sem, no entanto, examinar a contento o que essas noções possuem em comum; pressupondo, portanto, uma noção geral de representação, que articula as noções de sujeito e objeto ${ }^{30}$. Por outro lado, Kant também não teria realizado, correlativamente, uma teoria geral das faculdades cognitivas que viesse a lhe permitir conceber da maneira que concebeu faculdades como entendimento, sensibilidade e razão:

Na medida em que na filosofia o conhecimento do particular - no que diz respeito ao seu caráter científico, isto é, de necessidade e certeza apodítica - somente é determinado através do conhecimento do geral, nenhum conhecimento filosoficamente científico (philosophisch wissenschaftliche Erkenntnis) das faculdades sensível, intelectual e racional é possível sem um conhecimento exato e determinado da possibilidade da faculdade-rerpresentativa em geral. Tudo que se sabe sobre a faculdade-rerpesentativa, em geral, vale para sensibilidade, entendimento e razão, mas de modo algum o contrário ${ }^{31}$.

A ideia de edificar um sistema abrangente o suficiente de tal maneira que uma filosofia transcendental ou teoria do conhecimento empírico esteja fundamentada em uma teoria geral da representação e, correlativamente, uma teoria desta ou daquela faculdade cognitiva esteja fundamentada em uma teoria geral das faculdades se manterá em Schopenhauer ${ }^{32}$ só que, como veremos, na última seção

\footnotetext{
${ }^{30}$ A CRP tematiza sim a noção geral de representação, mas o faz assistematicamente, diria Reinhold. Talvez pelo respeito que manifestava ter por Kant, tenha feito com que Reinhold não tenha apresentado de maneira contundente os problemas que são encontrados na CRP quando nela se busca a sistematicidade fundamentacionalista almejada por Reinhold em sua Elemntarphilosophie; nessa perspectiva, se destacam duas ocorrências contraditórias de definições da noção de representação na CRP: "Todas representações, enquanto representações, possuem seu objeto" (A108). "O gênero é rerpesentação em geral. Subordinado a ele está representação com consciência (perceptio). Uma percepção que se relaciona somente com o sujeito como modificação de seu estado sensação (sensatio), uma percepção objetiva é cognição (cognitio) " (A320/B376-7) Ou seja, na CRP encontramos duas noções gerais de representação: uma em que toda representação tem objeto e outra que não.

${ }^{31}$ REINHOLD, K.L. Beyträge zur Berichtigung bisheriger Meißverständnisse der Philosophen, 178; [121].

${ }^{32}$ No próximo capítulo examinaremos a teoria geral das faculdades de Schopenhauer dando destaque ao seu caráter anti-kantiano que fundamentará sua crítica a Kant referente ao modo de articular conhecimento intuitivo e discursivo, que será examinada com maior detalhe no capítulo 5. Até o final deste capítulo mostraremos como o sistema de Schopenhauer pode ser compreendido como uma reformulação da Elemtharphilosophie de Reinhold.
} 
deste artigo, com modificações importantes que contemplam algumas críticas recebidas pelo projeto de Reinhold que precederam o abandono desse projeto por seu autor ${ }^{33}$.

\subsection{As noções de faculdade-representativa e representação da EP}

Apresentaremos agora o princípio absolutamente primeiro da Elementharphilosophie de Reinhold do qual - como estabelecera o seu autor - deveriam poder ser derivadas todas as teses relevantes da filosofia crítica.

Ocupa a primeira posição na hierarquia dos princípios o Princípio da Consciência (Satz des Bewußtseins):

$\mathrm{Na}$ consciência a representação, através do sujeito, do sujeito e do objeto se diferencia e com ambos se relaciona ${ }^{34}$.

Esse princípio é tomado como a expressão imediata de um fato: o fato da consciência. Trata-se, por isso, de uma descrição do que ocorre na consciência quando temos representações e supõe apenas uma "reflexão"35 sobre a própria. Porque esse princípio precisa ser absolutamente primeiro - para poder vir a ser considerado o princípio supremo de toda a filosofia ${ }^{36}$ - não apenas na exposição da teoria,

33 Cf. CASSIRER, E. Das Erkenntnisproblem in der Philosophie und Wissenschaft der Neuren Zeit, Band III: Die Nachkantischen Systeme, 1974. (1923), 57-8; BEISER, F. The Fate of Reason: German Philosophy from Kant to Fichtes, 1987, 263-5.

${ }^{34}$ REINHOLD, K.L., Beyträge zur Berichtigung bisheriger Meißverständnisse der Philosophen, 167; [113].

${ }^{35}$ É difícil determinar o que seria exatamente o que Reinhold queria chamar de "reflexão" e o que era demandado para que se pudesse conferir inteligibilidade ao seu princípio. (o fato de seu autor, diante de diversas críticas que recebera a respeito da inteligibilidade de seu primeiro princípio, ter abandonado este projeto, é um sinal de que talvez não se possa ter uma completa inteligibilidade do mesmo) Se trata, aparentemente, de uma investigação psicológica, no entanto, a priori, da consciência sobre a própria. A. Klemt (1958, p 58) sustentou que o que há de mais característico na Elementharphilosophie de Reinhold é uma análise descritiva do fato da consciência, coisa notavelmente semelhante com projeto fenomenológico de E. Husserl (apud HOYOS, L.E. El Escepticismo y la Filosofia Transcendental: Estudios sobre el pensamiento alemán a fines del siglo XVIII, 2001a, 59n.).

${ }^{36}$ Reinhold tem lá suas razões para fazer essa exigência; elas estão, fundamentalmente, calcadas na necessidade de conferir à filosofia crítica de Kant um caráter científico. Razões essas prolixamente expostas na $2^{\mathrm{a}}$ parte dos Beiträge (REINHOLD, K.L., Beyträge zur Berichtigung bisheriger Meißverständnisse der Philosophen, 1790, 93-164; [69-110]). Mais acessível é a compilação feita pelo Änesidemus (SCHULZE, G. E. Änesidemus oder über die Fundamente der von Herrn Professor Reinhold in Jena gelieferten Elementar-Philosophie, 1792, 49-55; [45-8]); Reinhold tinha uma exigência muito difícil de ser alcançada (talvez seja por isso que o Änesidemus as aceite completamente - o que, diga-se de passagem, é um belo recurso retórico para a defesa de uma posição cética-, Cf. (Schulze, Änesidemus oder über die Fundamente der von Herrn Professor Reinhold in Jena gelieferten Elementar-Philosophie, 1792, 53-57; [48-50])) por qualquer sistema filosófico e, sobretudo, pelo seu princípio primeiro. Esse princípio - que será identificado com o Satz de Bewusstseins - precisa ser o absolutamente primeiro de toda a filosofia e dele deve-se poder derivar todos as outras ciências e ramos da filosofia; através de seu conteúdo, esse princípio precisa conferir à filosofia "a unidade de uma ciência, na medida em que a necessidade de todos os outros princípios (Grundsätze) nele está fundamentada, e todos teoremas (Sätze), (...) devem poder a ele retornar, se existe [ de fato] 
mas psicologicamente falando, isto é, o princípio não pode ser antecedido por nenhum tipo de raciocínio ou inferência e por isso é descartado de antemão, por seu autor, que ele possa ter sido estabelecido através de uma abstração de inúmeros casos de representações observados, pois tal coisa faria com que o princípio deixasse de ser absolutamente primeiro ${ }^{37}$.

Os termos que fazem parte do princípio "sujeito", "objeto" e "representação" designam os próprios constituintes da consciência e, por isso, os conceitos que temos desses elementos da consciência são posteriores a esse fato e, por se referirem a ele, são determinações mediatas desse fato. Assim, cada um desses elementos da consciência tem origem na consciência mesma e não podem antecedê-la logicamente: essa é a razão de serem chamados por Reinhold de conceitos originários (ursprüngliche Begriffe).

Esses conceitos originários de sujeito, representação, e objeto são todos eles definidos a partir do princípio da consciência através "de um sutil procedimento refelxivo-analítico de dar voltas ao princípio da consciência como quando se dá uma forma determinada a uma massa de pizza" "38: "a representação é aquilo que, na consciência, se diferencia do sujeito e do objeto e com ambos se relaciona, através do

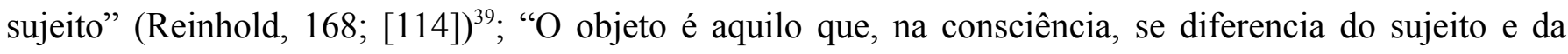
representação e com ambos se relaciona, através do sujeito"(ibid., 170; 115) " ;0 "O sujeito é aquilo que, na consciência, se diferencia do objeto e da representação e com ambos se relaciona, por meio de si mesmo" (ibid., 171; [116]) ${ }^{41}$.

Vejamos agora a definição de Vorstellungsvermögens (Faculdade-rerpesentativa):

Faculdade-representativa é aquilo através do que a mera representação é possível, isto é, aquilo que na consciência deixa-se relacionar com sujeito e objeto, mas que dos dois se diferencia; e que na causa da representação, isto é, naquilo que contém o fundamento da efetividade de uma representação, precisa existir antes de toda representação. ${ }^{42}$ (sublinhado por mim)

\footnotetext{
um tal princípio e ele está, consequentemente, seguro por si mesmo contra todo engano.” (Schulze, Änesidemus oder über die Fundamente der von Herrn Professor Reinhold in Jena gelieferten Elementar-Philosophie, 1792,.50; [46])

${ }^{37}$ Essa exigência - que é a causa de muitas dificuldades para Reinhold, Cf. SCHULZE, Änesidemus oder über die Fundamente der von Herrn Professor Reinhold in Jena gelieferten Elementar-Philosophie, 1792, 75-7; [61-3] - desaparecerá do primeiro princípio de Schopenhauer, como veremos adiante.

38 Apud HOYOS, L.E. El Escepticismo y la Filosofía Transcendental: Estudios sobre el pensamiento alemán a fines del siglo XVIII, 2001a, 59n.

${ }^{39}$ REINHOLD, K.L., Beyträge zur Berichtigung bisheriger Meißverständnisse der Philosophen, 1790, 168; [114].

${ }^{40}$ REINHOLD, K.L., Beyträge zur Berichtigung bisheriger Meißverständnisse der Philosophen, 1790, 170; [116].

${ }^{41}$ REINHOLD, K.L., Beyträge zur Berichtigung bisheriger Meißverständnisse der Philosophen, 1790, 171; [116].

42 REINHOLD, K.L., Beyträge zur Berichtigung bisheriger Meißverständnisse der Philosophen, 175-6; [119].
} 
A noção de faculdade representativa de Reinhold é concebida, fundamentalmente, através de uma analogia, a saber: uma faculdade representativa está para uma representação assim "como uma razão para sua conseqüência (wie jeder Grund von seiner Folge) e como uma causa para seu efeito". "33(Reinhold, 1790, 179; [122]) Ora, esse é justamente o modo de conceber as faculdades cognitivas que Kant declarou ser a razão de parecer ao leitor da CRP que sua dedução subjetiva era uma hipótese e que ele se prontificou a mostrar, em outra oportunidade, que nossas faculdades cognitivas não deveriam ser assim explicadas $^{44}$. Reinhold, desse modo, insistiu nesse modo de conceber nossas faculdades, contrariando a sugestão de Kant e dando margem a inúmeras críticas, dentre as quais se destacam as de Maimon e Schulze que, como veremos, são úteis para entendermos como Schopenhauer ${ }^{45}$ iria, mais tarde, edificar o seu sistema reformulando o abandonado e fracassado projeto de Reinhold.

\title{
1.3 A crítica dos céticos: Schulze e Maimon à noção de representação da EP
}

Voltemo-nos agora para a crítica à noção de representação de Reinhold proferida por Schulze:

\begin{abstract}
Durante o intuir obviamente não ocorre qualquer diferença entre um objeto e uma representação porque enquanto a intuição dura, nenhum objeto diferente dela é observado, em absoluto; a correspondência da diferença entre uma representação e um objeto destruiria imediatamente o intuir. Ora, uma vez que a intuição é uma espécie de representação, como o sr. Reinhold em todos seus escritos afirma, então existem, portanto, representações (...) que não contém aquilo que no §II se fez saber como nota necessária (notwendige Merkmal) de todas representações ${ }^{46}$.
\end{abstract}

A estratégia de Schulze é apresentar um contra-exemplo à noção de representação de Reinhold: a intuição não poderia ser uma espécie de representação se aquela definição de representação fosse mantida - "a representação é aquilo que, na consciência, se diferencia do sujeito e do objeto e com ambos se

\footnotetext{
${ }^{43}$ REINHOLD, K.L., Beyträge zur Berichtigung bisheriger Meißverständnisse der Philosophen, 1790, 179; [122].

44 "Uma vez que esta última questão [como é possível a própria faculdade de pensar] é, de certa maneira, a investigação da causa de um efeito dado e, nessa medida, também algo semelhante a uma hipótese (embora de fato não seja assim, como noutra ocasião mostrarei)..." (CRP: Axvii).

${ }^{45}$ A noção de faculdade-rerpesentativa de Reinhold é o que podemos chamar de um discurso de primeira ordem: "uma investigação psicológica das faculdades cognitivas". (BEISER, F. The Fate of Reason: German Philosophy from Kant to Fichte, 282) Schopenhauer, por outro lado, em sua teoria das faculdades faz o que poderíamos chamar de um discurso de segunda ordem: "elas [as faculdades cognitivas: sensibilidade, entendimento e razão] são expressões gerais para as classes de representações estabelecidas, que a cada época são mais ou menos precisamente diferenciadas naqueles poderes de conhecimento...". SW, III, 169-70, FR.209-10.

46 SCHULZE, G.E. Änesidemus oder über die Fundamente der von Herrn Professor Reinhold in Jena gelieferten Elementhar-Philosophie, 1792, 85-6; [68].
} 
relaciona, através do sujeito" - pois o relacionar e o diferenciar precisam, eles mesmos, ser concebidos como representações ${ }^{47}$. De modo que a consciência, ao se ocupar da relação e da diferença vigente entre objeto representado e sujeito representante, deixa de ter aquilo que é característico da intuição: a mera apresentação de um objeto. Desse modo, ao sermos conscientes da diferença de um objeto da própria representação, deixamos de ter consciência da apresentação do objeto. Assim, o conceito de representação de Reinhold é rejeitado por Schulze por ser "mais estrito do que pretende explicar" (enger als das Zuerklärende) ${ }^{48}$ porque não contempla, com a sua definição de representação, uma instância desejável de se incluir sob o conceito de representação: a intuição.

Ao comentar a censura de Änesidemus a Reinhold, Salomon Maimon afirma que, por um lado, se compreende por que Reinhold teria definido representação como se referindo e diferenciando do objeto: por ter importado sua noção de representação da tradição racionalista lebniziana que também concebia a noção de representação como uma relação a algo distinto, mas com uma ressalva: esse "algo distinto" era algo externo à consciência, a própria coisa em si. Maimon termina por advertir que não faz sentido para um adepto do idealismo transcendental manter uma referência de nossas representações a algo distinto e que para respeitar o uso correto da linguagem, a filosofia crítica deveria revogar completamente o conceito de representação e adotar outro: apresentação-parcial ${ }^{49}$. $(\text { Theildarstellung })^{50}$

\subsection{As críticas dos céticos à noção de faculdade representativa da EP}

Nesta seção veremos em que consiste a crítica do Änesidemus à teoria das faculdades de Reinhold e à filosofia crítica em geral, se compreendida exatamente do modo como Reinhold propunha ${ }^{51}$;

47 SCHULZE, Änesidemus oder über die Fundamente der von Herrn Professor Reinhold in Jena gelieferten Elementar-Philosophie, 1792, 87; [69].

48 SCHULZE, Änesidemus oder über die Fundamente der von Herrn Professor Reinhold in Jena gelieferten Elementar-Philosophie, 1792, 84; [68].

${ }^{49}$ A crítica desses céticos é apresentada aqui tendo em vista a alteração que Schopenhauer fará no conceito de representação de Reinhold através de uma substituição da cláusula que diferencia objeto e representação pela identidade desses elementos. Desse modo, Schopenhauer não chega a abandonar o termo representação da tradição filosófica que o precedeu, mas o conceito. As críticas desses filósofos a Reinhold também são interessantes para vislumbrarmos o destino do Idealismo Alemão - coisa que se percebe, notadamente, na resenha do Änesidemus realizada por Fichte - ao se suspender a referência a uma coisa externa à consciência, como sugere Maimon.

${ }^{50}$ MAIMON, S. Versuch über die Transscendentalphilosophie mit einem Anhang über die symbolische Erkenntniß und Anmerkungen, p.193, [319-21].

${ }^{51}$ É importante notar que o livro publicado anonimamente por Schulze sob o pseudônimo de Änesidemus tinha o seguinte título: Änesidemus oder über die Fundamente der von Herrn Professor Reinhold in Jena gelieferten Elementhar-Philosophie (Änesidemus ou sobre o fundamento da Elemntharphilosophie oferiecido em Jena pelo senhor professor Reinhold). Deve-se notar, igualmente, que grande parte do livro é dedicada a um exame minucioso da Elemntarphilosophie de Reinhold cuja motivação sempre foi complementar a tarefa realizada a contento por Kant, a saber: uma reforma na metafísica - uma resposta, 
finalizaremos a seção examinando os comentários de Maimon que, como mostraremos ao final do artigo, antecipa a teoria das faculdades de Schopenhauer: um discurso de segunda ordem sobre as condições de possibilidade de diferentes espécies de representações.

Änesidemus aceita as motivações de Reinhold para constituir o edifício da filosofia crítica sinteticamente a partir de um primeiro princípio; aceita o que Reinhold entende por primeiro princípio; aceita que uma filosofia com pretensões de cientificidade deva começar com a noção de representação, apesar de fazer inúmeras qualificações aos princípios de Reinhold ${ }^{52}$, mas rejeita a noção de faculdade-representativa esposada, tanto por Reinhold, como pela filosofia crítica em geral ${ }^{53}$. Em resumo, a estratégia de Reinhold em sua Elementharphilosophie seria a seguinte: todo cético aceita que temos representações, então deve aceitar também que temos faculdades representativas que são a causa de nossas representações. Esse último passo, Schulze não aceita. Trataremos de mostrar como se dá o argumento de Schulze contra Reinhold e contra - isto será importante para não desqualificarmos completamente o ceticismo de Schulze - a interpretação corrente da filosofia crítica de Kant na época: a interpretação de Reinhold. A questão levantada por Schulze, contra as pretensões da CRP de ter refutado o ceticismo de Hume, é basicamente a seguinte: o problema geral da CRP é responder como são possíveis juízos sintéticos a priori; indispensável para uma resposta a este problema é reconhecer que temos dois modos peculiares de conhecer e que nossa experiência está regulada por estes modos de conhecer, isto é, temos intuições e conceitos puros a priori. Mas esse reconhecimento pressupõe, segundo Reinhold, que tenhamos faculdades cognitivas que nos capacitem a conhecer através destes modos peculiares - o que seria o mesmo que pressupor que temos faculdades cognitivas. A questão levantada por Schulze é a seguinte: o que significa pressupor que temos faculdades cognitivas? O que devemos entender pela noção de sujeito transcendental da CRP? Que tipo de entidade não só Reinhold, mas Kant mesmo precisa

\footnotetext{
bem sucedida, a Hume e uma censura das pretensões da tradição racionalista e escolástica de utilizar os princípios do entendimento humano para além dos domínios de uma experiência possível. Tendo em vista esse contexto - a saber: a expectativa que se tinha da Elementarphilosophie de Reinhold e que até a publicação do Änesidemus era tida como alcançada devemos entender a pequena seção dedicada à filosofia de Kant e suas pretensões de ter refutado o ceticismo de Hume como uma redução ao absurdo da interpretação de Reinhold de Kant: se devemos entender a noção de sujeito transcendental da CRP do modo como a Elementharphilosophie de Reinhold defende, não temos nenhuma resposta a Hume, pois a CRP seria contraditória consigo mesma, como veremos na sequência do texto. Essas considerações são importantes para rejeitarmos a avaliação de BEISER (BEISER, F. The Fate of Reason: German Philosophy from Kant to Fichte, 283) da leitura de Schulze da CRP. A "leitura" de Schulze da CRP é a mesma de Reinhold, isto é, ele está mostrando que Reinhold não leu corretamente a CRP.

52 SCHULZE, Änesidemus oder über die Fundamente der von Herrn Professor Reinhold in Jena gelieferten Elementar-Philosophie, 1792, 49-47; [45-50].

53 SCHULZE, Änesidemus oder über die Fundamente der von Herrn Professor Reinhold in Jena gelieferten Elementar-Philosophie, 1792, 95-108; [74-83].
} 
pressupor para garantir que temos um aparato cognitivo e que, em última instância, é o que faz com que sejam possíveis juízos sintéticos a priori?

Apresentamos o resumo ${ }^{54}$ das críticas de Schulze à filosofia crítica, da maneira como expôs Beiser:

O conceito de sujeito transcendental de Kant é ambíguo; e em qualquer sentido que alguém venha a reconstruí-lo - seja como coisa-em-si, noumenon, ou idéia transcendental - não faz sentido pensá-lo como a origem ou fonte de conhecimento. Se ele é a coisa-em-si, então nós não podemos aplicar a categoria da causalidade a ele. Se, no entanto, ele é um noumenon, então ele, ou é uma entidade puramente inteligível ou a unidade formal da experiência (isto é, a unidade da apercepção; mas no primeiro caso, nós novamente aplicamos a categoria da causalidade além da experiência; e no segundo nós supomos que um mero conceito ou uma unidade abstrata cria a ordem da experiência.) Se, finalmente, é somente uma idéia transcendental, então nós não podemos atribuir um valor constitutivo a ele; pois Kant insiste que todas as idéias possuem somente um valor regulativo. ${ }^{55}$ (sublinhado por mim)

A questão de Schulze é a seguinte: podemos admitir que temos representações, mas devemos nos comprometer com que tipo de entidade para explicar que temos representações? No final das contas, a questão é: qual o estatuto ontológico desta primeira pessoa do plural implícita quando aceitamos a seguinte proposição: “temos representações”. O ceticismo de Schulze é implacável: qualquer tipo de entidade que identifiquemos como correspondente ao sujeito transcendental compromete os propósitos da filosofia crítica. Mas é importante notar que Schulze avalia se, através deste, ou daquele modo de se compreender a noção de sujeito transcendental da CRP podemos atribuir uma relação causal entre ela e os juízos sintéticos a priori: as disposições do ânimo que são as condições de possibilidade da experiência e, ao mesmo tempo, manter a coerência do espírito e da letra da CRP. Isto é, Schulze faz um exame "do fundamento oferecido por Reinhold" ${ }^{56}$ à filosofia transcendental de Kant e mostra que se esse fundamento for aceito, a CRP não pode ter refutado Hume, pois conceber a relação vigente entre as faculdades cognitivas e representações como a relação entre uma causa e um efeito, faz com que a CRP tenha que se comprometer com uma hipostasiação do "eu penso" e assim incorrer em contradição com a tese dos Paralogismos da Razão Pura, mais precisamente: o da substancialidade. (Cf. CRP: A348-51 e B407-11, B421-2)

\footnotetext{
${ }^{54}$ Utilizo aqui o resumo de Beiser para poupar nossos esforços. O texto de Schulze é denso e minucioso, revelando um profundo conhecimento e estudo da CRP.

${ }^{55}$ BEISER, F. The Fate of Reason: German Philosophy from Kant to Fichte, p.281.

${ }^{56}$ Cf. o título do texto de SCHULZE, a saber: Änesidemus oder über die Fundamente der von Herrn Professor Reinhold in Jena gelieferten Elementar-Philosophie; traduzindo: Änesidemus ou sobre os fundamentos da Filosofia dos Elementos defendida pelo Professor Reinhold de Jena.
} 
A questão central que a CRP deveria responder para refutar Hume seria: como são possíveis juízos sintéticos a priori? Schulze tenta mostrar que esta questão não é respondida nem por Kant, nem por Reinhold ${ }^{57}$ - ou, como viemos advertindo, por "um Kant" interpretado nos moldes da filosofia de Reinhold, como na época era o caso - pois, ao entender as faculdades cognitivas como causa de nossas representações, a própria CRP perde sua consistência interna. Uma faculdade em geral não só seria o que torna a representação possível, mas o que atuaria como causa da efetividade da representação ${ }^{58}$, isto é, cairíamos em uma hipostasiação das faculdades: como causa da efetividade das representações elas precisariam ser realmente distintas delas.

Mas Kant, que não se comprometeu com nenhuma das alternativas de correspondência elencadas por Schulze, teve, positivamente, o sentido de sua noção de sujeito transcendental esclarecido, mais tarde, "pelo adversário que melhor o compreendeu"59. Maimon entra no debate com Schulze e Reinhold e apresenta uma interpretação da noção de faculdade representativa, segundo a qual a filosofia crítica não precisa se comprometer com nenhum tipo de correspondência ontológica para suas noções mais fundamentais:

A explicação do Sr. Reinhold de faculdade em geral, a qual ele na sua explicação de faculdade representativa fundamenta, está incorreta. "Faculdade-representativa é aquilo através do que a mera representação é possível, portanto é a faculdade geral do fundamento da possibilidade de uma coisa"; mas isto não só é contra toda terminologia filosófica, mas não faz absolutamente qualquer sentido. (...)

Agora, uma vez que de acordo com a filosofia crítica, o sujeito das representações é para nós um mero conceito formal, não pode ele ser chamado de "poder de representações" enquanto faculdade representativa porque tanto um como o outro pressupõe um objeto real e uma relação real (de causalidade). Deveria o Sr. Reinhold ter entendido sob faculdade representativa não o fundamento real da efetividade (a causa) das representações, mas somente isto comum a todas representações efetivas, assim como, por exemplo, a lei de atração, que não é entendida como "causa da atração", mas somente o modo geral ou a lei segundo a qual a atração ocorre; deste modo, no presente caso, "faculdade representativa" seria de modo algum algo distinto da mera representação (que este geral combina). ${ }^{60}$ (sublinhado por mim)

57 SCHULZE. Änesidemus oder über die Fundamente der von Herrn Professor Reinhold in Jena gelieferten Elementar-Philosophie, 1792; 130-80; [98-129].

${ }^{58}$ Essa é uma distinção apontada por Maimon em seu comentário ao Änesidemus, mais precisamente em sua Dritter Brief des Philaletes na Änesidemus. MAIMON, S., Versuch über die Transscendentalphilosophie mit einem Anhang über die symbolische Erkenntniß und Anmerkungen, p. 203, [338-9].

${ }^{59}$ Vide carta de Kant a Herz, de 26 de maio de 1789.

${ }^{60}$ MAIMON, S., Versuch über die Transscendentalphilosophie mit einem Anhang über die symbolische Erkenntniß und Anmerkungen, 201-2, [334-36]. 
Maimon reclama por uma interpretação bem diferente daquela oferecida por Reinhold da noção de faculdade-rerpesentativa; uma interpretação compatível com aquela afirmação de Kant sobre uma futura teoria das faculdades que ele pretendia oferecer e assim remover a impressão dos leitores da DT que ele lidava com hipóteses na CRP - ao utilizar uma dedução subjetiva sem o poder persuasivo que ele almejava: não deveríamos entender uma teoria das faculdades como uma investigação etiológica. (Axvii) Isto é, a CRP não se compromete com uma investigação psicológica sobre as faculdades cognitivas. Esse resultado estava já latente no ceticismo de Schulze, que consistiu em mostrar que Reinhold não tinha compreendido Kant corretamente. Desse modo, Maimon complementa a censura de Schulze a Reinhold mostrando que a CRP não precisa se comprometer com a atribuição de qualquer tipo de entidade à noção de sujeito transcendental para responder ao seu problema central: como são possíveis juízos sintéticos a priori? Como vimos na passagem acima, de acordo com a interpretação oferecida por Maimon, a filosofia crítica precisa se comprometer somente com um " $\mathrm{x}$ " suficiente para explicar que temos representações, isto é, a CRP não precisa determinar que tipo de entidade seja o sujeito transcendental, assim como a física não precisa determinar que tipo de entidade corresponda a uma lei da natureza para explicar os fenômenos que explica. Assim, a interpretação de Reinhold, que se comprometia com uma hispostasiação do "eu penso", pois compreendia a relação entre faculdades cognitivas e representações como a relação entre causa e efeito padece do problema apontado por Beiser ${ }^{61}$ de realizar uma teoria geral das faculdades como um discurso de primeira ordem sobre as faculdades cognitivas: "uma investigação psicológica das faculdades cognitivas”. Mas Beiser atribui este erro de interpretação à leitura que Schulze fizera de Kant e atribui a este último ${ }^{62}$ uma tolerância a esse tipo de discurso ao que seria a sua dedução subjetiva e não àquele que seria o seu objetivo principal. Ora, como viemos advertindo, Kant manifestou ter o projeto de desenvolver uma teoria das faculdades que não seria uma investigação etiológica, coisa que veremos desenvolvida na teoria das faculdades de Schopenhauer.

\subsection{Schopenhauer e o projeto de fundamentação de uma teoria das faculdades cognitivas: a retomada do projeto de Reinhold e soluções dos problemas apontados pelos céticos}

Trataremos agora de mostrar que a teoria das faculdades de Schopenhauer pode ser vista como uma reformulação da Elementarphilosophie de Reinhold. Defenderemos essa tese mostrando que

\footnotetext{
${ }^{61}$ BEISER, F. The Fate of Reason: German Philosophy from Kant to Fichte, 282-3.

${ }^{62}$ BEISER, F. The Fate of Reason: German Philosophy from Kant to Fichte, 283n.
} 
Schopenhauer possui um sistema de filosofia transcendental que mantém as características da Elementarphilosophie de Reinhold e que possui características que podem ser entendidas como modificações que contemplam as críticas dos céticos, que apresentamos acima, bem como dificuldades inerentes ao projeto de Reinhold.

O primeiro princípio da filosofia de Schopenhauer é um princípio epistemológico; exprime aquilo que inegavelmente se encontra em qualquer cognição: uma consciência que representa, para si mesma, objetos, os quais se conectam entre si podendo formar uma cadeia complexa de relações. No momento, não é nosso objetivo examinar o primeiro princípio da filosofia de Schopenhauer enquanto tal, mas apenas mostrar que Schopenhauer possuía um sistema de filosofia que muito deve à EP de Reinhold; de modo que nos concentraremos ao longo desta seção em encontrar semelhanças e diferenças desses projetos; iniciamos apresentando o primeiro princípio de $\operatorname{Schopenhauer}^{63}$ :

\section{A raiz do Princípio de Razão Suficiente}

Nossa consciência cognitiva (erkennendes Bewußtsein), enquanto sensibilidade interna e externa (receptividade), compreendendo entendimento e razão, decompõe-se em sujeito e objeto e não contém nada além disso. Ser objeto para o sujeito e ser nossa representação são o mesmo. Todas as nossas representações são objetos do sujeito e todos os objetos do sujeito são nossas representações. Ora, acontece que todas as nossas representações estão relacionadas umas com as outras de acordo com uma ligação determinável a priori; por isso nada pode se tornar objeto para nós por si constituído e independente, assim como nenhum objeto pode ser isolado e simples ${ }^{64}$.

No exame comparativo que faremos com a EP de Reinhold nos concentraremos no problema da consciência; deixaremos de lado, portanto, o problema do princípio de razão suficiente, que diz respeito à conexão necessária entre os objetos ${ }^{65}$.

\footnotetext{
${ }^{63}$ Em duas passagens Schopenhauer declara que o primeiro princípio da filosofia possui como objeto a consciência e o princípio de razão, que articula a relação entre os fenômenos: (SW, I, 134-36; MVR 1: 91-92), (SW, II, 166). Nessas passagens a filosofia é caracterizada como tendo a função de tematizar aquilo que todas as ciência supõem e expressar, através de um número pequeno de conceitos gerais, toda a diversidade encontrada no mundo, que aparece, sempre como representação de um sujeito.

${ }^{64}$ SCHOPENHAUER, A. SW, III, 41, PR: $\$ 16$.

${ }^{65}$ Essa é uma restrição que se impõe devido ao fato de que em nossa pesquisa ainda não foi possível realizar um exame da contenda sobre o princípio de razão suficiente que precedeu a entrada de Kant no debate com Eberhard. Sabemos que antes dessa manifestação de Kant, o debate tinha Reinhold como um defensor da filosofia crítica. Reconhecemos, portanto, que nossa pesquisa aqui apresentada pode ser desenvolvida através de um exame desse outro debate que ocorreu na recepção da filosofia de Kant. Até o momento pudemos apenas nos concentrar no projeto de fundamentação de uma teoria das faculdades em um princípio primeiro que Reinhold se propôs a desenvolver, por isso precisamos reconhecer a limitação de nossa pesquisa no que diz respeito a uma investigação exaustiva das motivações do projeto filosófico de Schopenhauer: o primeiro princípio que funda sua teoria das faculdades não contém apenas elementos de uma resposta ao projeto de uma EP, mas também para responder ao debate sobre o princípio de razão suficiente.
} 
De início, destacamos que Schopenhauer possuía um projeto fundacionalista que consiste em partir de um fato da consciência (Tatsache des Bewusstseins):

Nós não partimos nem do objeto nem do sujeito; mas da representação, que já contém e pressupõe ambos, uma vez que a sua forma mais geral e essencial é o decompor em objeto e sujeito ${ }^{66}$.

(...) nós não partimos nem do sujeito nem do objeto, mas da representação como primeiro fato da consciência ${ }^{67}$.

Partir de um fato da consciência como primeiro princípio e a partir disso edificar um sistema de filosofia é, como vimos, justamente o que fez Reinhold e, a partir dele, um considerável grupo de filósofos na recepção da filosofia de Kant desenvolveu e reformulou esse projeto ${ }^{68}$. Na passagem acima, podemos ver que Schopenhauer, assim como Reinhold, parte também do chamado "fato da consciência", apesar desse fato precisar ser compreendido de uma maneira distinta, dadas as características que distinguem o sistema de Schopenhauer do de Reinhold, as quais serão apresentadas ao longo desta seção. Assim, ao final desta seção, depois de determinarmos as diferenças dos sistemas de Schopenhauer e Reinhold, retomaremos as semelhanças e mostraremos até que ponto elas se mantêm. Isso não se dará exclusivamente para o caso do fato da consciência, mas para todas as semelhanças que podemos encontrar nos dois sistemas, como por exemplo para o caráter analítico do primeiro princípio do qual os sistemas de Schopenhauer e Reinhold partem:

(...) em geral, um objeto sem sujeito não é concebível sem contradição ${ }^{69}$.

(...) todo conhecimento pressupõe inevitavelmente sujeito e objeto ${ }^{70}$.

\footnotetext{
${ }^{66}$ SCHOPENHAUER, A. SW, I, 59-60.
}

${ }^{67}$ SCHOPENHAUER, A. SW, I, 71.

${ }^{68}$ Eis uma passagem, de um discípulo de Kant, que nos mostra como surgiram inúmeros projetos filosóficos no período de recepção da filosofia de Kant: "Há senhores que estão ocupados em construir uma filosofia dos elementos através da qual eles acreditam estar erguendo sob a Crítica o fundamento que o seu grande autor supostamente negligenciou prover, pelo menos em algumas formas desenvolvidas. (...) Eles querem levar argumentos da filosofia crítica até o nível de fatos reais (actual fact). Mas, o fato do qual toda filosofia deve ter origem, de acordo com um deles, é o princípio de contradição; de acordo com outro, o princípio da consciência; ainda de acordo com um terceiro, o princípio de animação; para um quarto, o princípio de determinabilidade; para um quinto, o princípio de subjetividade (selfhood), etc." BECK, J.S. Explanatory Abstract of the Critical Writing of Prof. Kant, Prepared with the Same, p.136. Para maiores detalhes sobre o período, cf. DIGIOVANNI, 2000, HOYOS, 2001, BEISER, 1993, CASSIRER, 1974.

${ }^{69}$ SCHOPENHAUER, A. SW, I, p.46.

${ }^{70}$ SCHOPENHAUER, A. SW, III, p.168. 
Como imediatamente com o sujeito se coloca o objeto (do contrário a palavra não teria significado)... ${ }^{71}$.

Assim, o princípio do qual parte Schopenhauer para promover a edificação de seu sistema é um princípio analítico. Até o final deste artigo, retornaremos à questão da analiticidade do primeiro princípio da filosofia de Schopenhauer. No momento, prosseguiremos assinalando características comuns aos projetos de filosofia primeira de Schopenhauer e Reinhold: a teoria das faculdades do sistema de Schopenhauer é concebida a partir daquele primeiro princípio e depende de como a relação entre as noções lá contidas são concebidas. Assim, como acontecia na Elementarohilosophie de Reinhold, o primeiro princípio do sistema de Schopenhauer que articula as noções de representação, sujeito e objeto fundamenta uma teoria das faculdades cognitivas.

(...) faculdades cognitivas relacionam-se (...) com as classes de representações exatamente da mesma maneira que sujeito em geral com objeto em geral. Como imediatamente com o sujeito se coloca o objeto (do contrário a palavra seria sem significado) e, da mesma maneira, o sujeito com o objeto; e, portanto: ser-sujeito significa exatamente o mesmo que ter um objeto, assim como ser-objeto significa ser conhecido por um sujeito. Exatamente da mesma maneira é o caso com um objeto de alguma maneira determinado: imediatamente coloca-se também o sujeito conhecendo da mesma maneira. Uma vez que é indiferente se eu digo: os objetos têm tais e tais determinações que a ele são inerentes e próprias; ou: o sujeito conhece de tal e tal maneira - é também indiferente se eu digo: os objetos se dividem em tais classes; ou: ao sujeito são peculiares tais e tais poderes de conhecimento. ${ }^{72}$ (sublinhado por mim)

Seria possível, a partir dessa passagem, seguir um exame detalhado da teoria das faculdades de Schopenhauer, mas aqui nos interessa apenas o fato de que a noção de faculdade cognitiva do sistema de Schopenhauer é concebida a partir das noções que estão contidas em seu primeiro princípio: a relação recíproca entre sujeito e objeto é transferida para a relação entre faculdades cognitivas e classe de objetos. Nisso constatamos uma herança da Elementarphilosophie de Reinhold que não pode ser encontrada na filosofia crítica de Kant, a saber: a tentativa de fundamentação de uma teoria das faculdades em noções mais fundamentais. É importante adiantar dois pontos relacionados a essa semelhança dos projetos de Schopenhauer e Reinhold: (i) a razão que faz com que Schopenhauer conceba a noção de faculdade cognitiva como dependente da noção de classe de objetos, da mesma maneira que as noções de sujeito e objeto, contém uma importante diferença em comparação com o projeto de Reinhold: as noções de ‘sujeito' e ‘objeto’ são as noções mais abstratas do sistema, enquanto as noções de 'faculdade cognitiva' e

${ }^{71}$ SCHOPENHAUER, A. SW, III, p. 170.

${ }^{72}$ SCHOPENHAUER, A. SW, III, 169-70, PR: 209-10. 
'classe de objetos ou representações' estão em um nível abaixo, portanto, no sistema de Schopenhauer, tanto o primeiro princípio como a noção de faculdade cognitiva são resultado de uma abstração; (ii) embora a idéia de fundamentar uma teoria das faculdades em noções mais gerais seja completamente estranha ao escopo da CRP, a tese resultante da teoria das faculdades de Schopenhauer, incompatível com um pressuposto fundamental da CRP, será utilizada por Schopenhauer para acusar Kant de contradição.

Passaremos agora a considerar as diferenças dos projetos de Schopenhauer e Reinhold, tratando de mostrar também em que medida essas diferenças podem ser entendidas como reformulações e aprimoramentos do projeto de Reinhold. Dentre as diferenças do projeto de Schopenhauer uma se destaca por se relacionar de um modo peculiar com as demais: a diferença que diz respeito ao método. Schopenhauer critica os sistemas filosóficos que lançam mão de derivações puramente lógicas e caracteriza o seu procedimento metodológico como analítico ou indutivo, tanto na ordem da descoberta, como na ordem de exposição. Pois bem, o fato é que embora Schopenhauer se manifeste a respeito do método utilizado por ele nos princípios de sua filosofia transcendental, ele o faz de maneira insuficiente para podermos determinar adequadamente o que ele chama de deduções "não puramente lógicas", que ele entende como as únicas derivações legítimas. Essa insuficiência de esclarecimentos sobre o método de sua filosofia nos demandará recorrer a esclarecimentos relacionados com o que ele entende por derivações genuínas, não-puramente lógicas, que ele nos apresenta estabelecendo como deve ser o procedimento para edificar o corpo doutrinário de uma ciência; os quais são, na verdade, esclarecimentos que dizem respeito ao modo de geração dos conceitos fundamentais que fazem parte dos primeiros princípios de uma ciência. Coisa que nos permitirá compreender como Schopenhauer procedeu para a formação dos conceitos fundamentais que fazem parte do primeiro princípio de sua filosofia. Ao final, pretendemos mostrar que a concepção de método do sistema de Schopenhauer, por um lado possibilita algumas modificações do projeto de Reinhold, por outro, resolverá problemas intrínsecos a esse.

Nos outros sistemas filosóficos a conseqüência é trazida pronta através de uma dedução de princípio a princípio. Mas para isso ocorrer o próprio conteúdo precisa estar já presente em todos os princípios mais gerais. (...) [Nesses sistemas] só é desenvolvido e repetido o que já tinha sido dito nos princípios fundamentais. (...) Meus princípios, ao contrário, freqüentemente, apóiam-se não nas conclusões, mas imediatamente no mundo intuitivo; as conseqüências no meu sistema são como qualquer conseqüência real e rigorosa, as quais, via de regra, não são alcançadas por uma via puramente lógica ${ }^{73}$.

A respeito do caráter próprio do meu filosofar, posso dizer que em toda parte procuro levar as coisas ao fundamento real, na medida em que eu não sossego até perseguí-las até

${ }^{73}$ SCHOPENHAUER, A. SW, IV, 163. 
o último dado (Gegebene). Isto acontece de acordo com uma tendência natural que me impele a não descansar com qualquer conhecimento mais geral e mais abstrato consequentemente, ainda mais indeterminado - seja com conceitos puros, seja com palavras; mas [esta tendência natural] me impulsiona a ter nus frente a mim os últimos princípios de todos conceitos e proposições, que são sempre intuitivos, os quais então eu preciso, lá deixar como fenômenos originários (Urphänomen) ${ }^{74}$.

Essas passagens nos mostram que Schopenhauer tinha concepção metodológica distinta da de Reinhold. Pois este, como vimos, pretendia deduzir sua teoria das faculdades de seu primeiro princípio, o princípio da consciência (Satz des Bewusstseins), o qual continha as noções de sujeito, objeto e representação. Schopenhauer claramente manifesta não fazer isso em seu sistema, pois, dessa forma, do conteúdo do primeiro princípio deveria poder ser derivado todo o sistema. Mas essa passagem não é clara sobre o que Schopenhauer entendia por uma derivação não puramente lógica dos teoremas de seu sistema e nem como esses elementos extra-lógicos ou dados intuitivos poderiam fazer parte das derivações promovidas por seu sistema. No entanto, está claro e manifesto que Schopenhauer rejeita o método de investigação e de exposição sintética ou dedutiva: "Tudo o que aqui foi dito resume-se na seguinte frase: minha filosofia não se originou e não se apresentou através da via sintética, mas através da analítica", ${ }^{75},{ }^{76}$

Ao se pronunciar sobre o modo com o qual o corpo doutrinário de uma ciência deve ser formado, Schopenhauer faz afirmações sobre as limitações das deduções lógicas e a importância do material pré-judicativo, as representações intuitivas, para a formulação de premissas. Essas considerações todas dependem do modo como Schopenhauer concebe o juízo e a relação entre intuições e conceitos: todo juízo é uma relação de esferas de aplicação ou extensão de conceitos, os quais têm o seu conteúdo originado através de um processo de abstração de intuições ${ }^{77}$. Schopenhauer afirma que a ciência se caracteriza "pela marcha gradual do geral ao particular", de modo que "a maior parte de suas proposições são derivadas de princípios admitidos previamente, isto é, são fundadas sobre provas". Mas "toda prova se apóia numa verdade incomprovada, que é o próprio fundamento da prova, ou das provas da prova". De modo que "a intuição - seja pura e a priori; como nas matemáticas, seja a posteriori, como nas outras ciências - é a

\footnotetext{
${ }^{74}$ SCHOPENHAUER, A. SW, IV, 164.

${ }^{75}$ SCHOPENHAUER, A. SW, IV, 164.

76 Nessa frase temos uma clara manifestação de um desacordo com o método utilizado por Reinhold em sua EP e a manifestação de que Schopenhauer possui uma concepção metodológica peculiar. Convém mencionar que essas três últimas passagens citadas são encontradas em textos tardios; passagens nas quais Schopenhauer oferece esclarecimentos sobre sua própria filosofia (Einige Bemerkungen über meine eigene philosophie). (SW, IV, §14) Por incrível que pareça, elas são as afirmações mais diretas sobre o modo com o qual Schopenhauer teria formado e exposto o seu sistema de filosofia primeira. Com o intuito de esclarecer mais a questão, utilizaremos passagens de outros textos vinculados ou á tarefa da filosofia em geral, ou ao método das ciências.

${ }^{77}$ Uma passagem curta em que essa tese é expressa: “todo conceito existe e tem valor enquanto está em relação, tão longínqua quanto se queira, com uma representação intuitiva”. (MVR 1: 74).
} 
fonte de toda verdade e o fundamento de toda ciência.” (MVR 1: 73) Schopenhauer, portanto, vê restrições nas derivações lógicas e as considera incapazes de nos oferecer conhecimento sem recorrer a elementos extra-lógicos:

Nenhuma ciência pode ser totalmente dedutiva, tal como não se pode construir no ar; todas as suas provas devem reconduzir-nos a uma intuição que já não é demonstrável...

Não se chegará nunca, com um encadeamento puramente lógico de silogismos - por mais certas que sejam as premissas -, senão a esclarecer a matéria que reside completamente nas premissas... ${ }^{78}$

Essas considerações sobre o método das ciências são encontradas no primeiro volume de MVR; no segundo volume dessa mesma obra, encontramos, no capítulo $12^{79}$, uma exposição sistemática sobre como deve ser estabelecido um corpo doutrinário em geral; passagem na qual é possível perceber o modo exato com o qual Schopenhauer concebia o estabelecimento dos primeiros princípios de um corpo doutrinário, passando por uma geração de conceitos a partir de uma comparação com a realidade empírica e com resultados já consagrados no campo do saber em questão:

Da análise das várias funções do nosso intelecto (...) está claro que para um correto uso metodológico, seja para um propósito prático ou teórico, o seguinte é exigido: (1) a correta apreensão intuitiva das coisas reais tomadas em consideração e todas as suas relações e propriedades essenciais de todos dados (Data);(2) A formação (Bildung) a partir destas de conceitos corretos, portanto o resumo (Zusammenfassung) daquelas propriedades sob correta abstrações que então se tornam o material do pensamento subseqüente. (3) A comparação destes conceitos parcialmente com o intuído, parcialmente com eles mesmos, parcialmente com o estoque de conceitos restantes, de maneira que resulte disso juízos corretos, apropriados ao assunto, compreendendo e exaurindo o assunto completamente. (4) A reunião ou combinação desses juízos em premissas de silogismos: isso pode variar de acordo com a escolha e arranjo dos juízos e ainda o resultado real de toda a operação é primariamente dependente disso ${ }^{80}$.

A passagem deixa explícito algo que já havíamos anteriormente manifestado: a concepção metodológica defendida por Schopenhauer supõe sua teoria sobre o conhecimento discursivo (conceitos são abstrações de intuições e juízos são relações entre conceitos; silogismos são relações entre juízos). A imposição dessa concepção metodológica à filosofia, realizando os ajustes necessários para uma adequação à matéria - coisa com a qual nos comprometemos em nossa interpretação e para a qual, em

\footnotetext{
${ }^{78}$ SCHOPENHAUER, A. MVR I: 74-75.

${ }^{79}$ SCHOPENHAUER, A. SW, IV, 155-168.

${ }^{80}$ SCHOPENHAUER, A. SW, II, 155-6.
} 
seguida, apresentaremos evidências textuais que a atestam - dá margem a uma objeção que nos será útil para esclarecer a peculiaridade do método utilizado por Schopenhauer em seu projeto fundacionalista. A objeção é uma acusação de circularidade: “como um sistema cujo objetivo é oferecer uma teoria das faculdades cognitivas, que deve determinar como qualquer faculdade cognitiva deve ser concebida, pode pressupor uma teoria sobre o conhecimento discursivo? Essa teoria deveria estar subsumida a uma teoria das faculdades e não ao contrário.”

A questão é que Schopenhauer possui um projeto fundacionalista, mas ele está imbuído de um certo pragmatismo que antecipa aquilo que encontramos na descrição de Goodman ${ }^{81}$ do equilibro reflexivo na justificação de inferências dedutivas: não se deriva uma conseqüência exclusivamente de um princípio aceito anteriormente, mas se faz um acordo entre resultados previamente aceitos e princípios ${ }^{82}$. Segundo essa concepção, as derivações promovidas por um corpo doutrinário não seguem uma linha descendente de um princípio geral ou um axioma até chegar a teoremas, por uma via puramente lógica, mas a determinação do próprio conteúdo dos princípios gerais demanda um prévio conhecimento de teses que posteriormente serão encaradas como teoremas do sistema. De modo que na confecção de um corpo doutrinário não se procede admitindo inicialmente o princípio supremo e dele derivando todos os teoremas do sistema, mas se parte de resultados irrecusáveis e, procedendo por abstração e comparação, se determina os princípios primeiros. Mas, uma vez concebidos esses princípios, deles será necessário poder derivar aqueles resultados dos quais se partiu para a determinação dos primeiros princípios, mas daí esses resultados serão teoremas. Ou seja, a própria formulação dos princípios do sistema antevê aquilo que deles será derivado.

Essa objeção que tratamos de rechaçar se relaciona com o que Schopenhauer deve ter feito para conceber sua teoria das faculdades e o seu primeiro princípio, dado que o seu procedimento metodológico é aquele descrito na passagem acima: o primeiro passo é a consideração dos dados. Ora, os dados para que venha a ser estabelecida uma teoria das faculdades são as próprias cognições, ou, como podemos depreender da tese de doutorado de Schopenhauer, diferentes tipos de juízos, os quais demandam diferentes tipos de justificativas, as quais pressupõem fontes heterogêneas de $\operatorname{cognições}{ }^{83}$. A

${ }^{81}$ GOODMAN, N. Fact, Fiction and Forecast, 1979, 62-65.

82 "Um círculo virtuoso", no qual há "ajustes mútuos entre regras e inferências aceitas". GOODMAN, N. Fact, Fiction and Forecast, 64.

${ }^{83} C f$. PR: $§ 15, \S 51, \S \S 28-33$; passagens em que se evidencia que Schopenhauer toma as diferentes maneiras de encontrarmos a razão ou justificativa da verdade de um juízo (Erkenntnisgrund) como possibilitadas por diferentes poderes cognitivos. Por exemplo: a razão para o juízo "a soma dos ângulos de um triângulo é $180^{\circ}$ " não é de mesma natureza que "aquele livro é amarelo"; no primeiro caso, a justificativa do juízo repousa, em última instância, em uma intuição pura, no último, em uma intuição empírica. 
partir desses dados se passa para o processo de formação de conceitos de faculdade cognitiva e, posteriormente, o de representação, sujeito e objeto, os quais são os mais gerais.

O fato é que, diferentemente do corpo doutrinário das ciências, quando a formação dos conceitos que serão conectados na formação dos princípios é feita a partir de comparações com a realidade empírica, com as intuições, o corpo doutrinário da filosofia deve ser montado com juízos que têm por objeto tudo que as ciências pressupõem: as relações elementares que se encontram em todas nossas cognições. ( $C f$. PRS:§16) Assim, os conceitos que farão parte dos princípios da filosofia devem ser gerados a partir de uma comparação com todas as nossas cognições. Corroborando a nossa interpretação sobre o método da filosofia que Schopenhauer teria concebido, a qual realizamos a partir de uma consideração de passagens sobre o método das ciências, estão essas passagens nas quais Schopenhauer expõe ser a tarefa da filosofia obter uma compreensão da essência do mundo:

[a filosofia] deve servir-se da abstração, pensar todo o particular sob a forma do geral e compreender todas as diferenças do particular sob a um conceito geral. Assim, ela deverá, por um lado, separar, por outro, reunir e entregar ao conhecimento toda a multiplicidade do mundo reduzida a um pequeno número de conceitos essenciais.

Sem dúvida, poderá alegar-se que cada um sabe o que é o mundo, sem procurar tão longe, visto que cada um é o sujeito do conhecimento e o mundo é a sua representação (...).

A harmonia que reina no mundo, sob todos os seus aspectos e em cada uma de suas partes, pelo fato de pertencer a um todo, deve encontrar-se também nessa imagem abstrata do mundo ${ }^{84}$.

Uma comparação dessas passagens que estabelecem tarefas à filosofia para elaboração de uma ‘imagem abstrata do mundo’ com o $§ 16$ de PRS nos fornece evidências suficientes para sustentarmos que o método utilizado por Schopenhauer na formulação dos princípios de seu sistema foi justamente aquele, mutatis mutandis, que encontramos descrito detalhadamente para a formação dos princípios do corpo doutrinário de uma ciência. Não consideramos essa questão já estabelecida, no entanto. Até o final deste artigo mostraremos como as diferenças que encontramos nos projetos de filosofia primeira de Schopenhauer e Reinhold podem ser explicadas aceitando que o método da filosofia de Schopenhauer deve ser compreendido dessa maneira que sustentamos.

Comecemos pela diferença mais gritante. Comparemos o modo com o qual as noções de sujeito objeto e representação estão articuladas no primeiro princípio da filosofia de Reinhold e Schopenhauer:

\footnotetext{
${ }^{84}$ SCHOPENHAUER, A. MVR I, 91-2.
} 
$\mathrm{Na}$ consciência a representação, através do sujeito, do sujeito e do objeto se diferencia e com ambos se relaciona ${ }^{85}$.

Nossa consciência cognitiva, (...), decompõe-se em sujeito e objeto e contém nada além disso. Ser objeto para o sujeito e ser nossa representação é o mesmo. ${ }^{86}$ (sublinhado por $\operatorname{mim})$

A mera consideração da disposição dos elementos que compõem os primeiros princípios de Reinhold e Schopenhauer que, como já mencionamos acima, são os mesmos, nos permite identificar uma contradição: enquanto Reinhold diferencia "representação" e "objeto", Schopenhauer os identifica. Essa cláusula que identifica objeto e representação é uma diferença do primeiro princípio de Schopenhauer e do de Reinhold que nos mostra que o debate em torno dos princípios da filosofia crítica não terminou em 1794, com a Doutrina da Ciência de Fichte, que se apresenta com uma resposta a Schulze e Maimon. Pretendemos mostrar que, concebendo o método da filosofia de Schopenhauer da maneira como sugerimos acima, é possível entender a cláusula que diferencia gritantemente o princípio do §16 de PRS do princípio da consciência de Reinhold como uma reformulação promovida por Schopenhauer que contempla as críticas de Schulze e Maimon ao princípio da consciência de Reinhold que vimos na seção anterior. Assim, defenderemos a tese exegética segundo a qual esses céticos, juntamente com Reinhold, forneceram boa parte do horizonte conceitual e problemático dos princípios da filosofia de Schopenhauer ${ }^{87}$.

Como vimos, a cláusula da diferenciação entre representação e seu objeto foi atacada por Schulze através de um contra-exemplo. Alegava Schulze que se a representação sempre se relaciona a um objeto diferente dela, a intuição não poderia ser um tipo de representação. Ora, a aplicação de um dos procedimentos contidos naquela descrição de passos de formação de um corpo doutrinário contempla algo como as objeções que os céticos fizeram a Reinhold, caso Schopenhauer as considerasse pertinentes, como nos parece ser o caso: a formação correta dos conceitos que compõem o princípio de uma doutrina deve levar em conta os resultados consagrados no campo em questão. De modo que antes de formular um juízo que conectasse os conceitos de sujeito, objeto e representação, Schopenhauer - caso tenha seguido o procedimento por ele descrito, como aqui estamos supondo - deve ter considerado duas coisas que se

\footnotetext{
${ }^{85}$ REINHOLD, K.L. Beyträge zur Berichtigung bisheriger Meißverständnisse der Philosophen, $167 ; 113$.

${ }^{86}$ SCHOPENHAUER, A. SW, III, 41.

${ }^{87}$ Outros problemas da recepção da filosofia de Kant também são contemplados no sistema de Schopenhauer: o problema da afecção, apontado por Jacobi, primeiramente, e a própria contenda entre Kant e Eberhard: Schopenhauer apresenta o que ele chama de uma "nova dedução da coisa em si" (SCHOPENHAUER, A., SW, I, 570) e uma dedução do Princípio de Razão Suficiente como princípio supremo de todo o sistema de filosofia transcendental ( $C f$. PR: $\S 16$ ).
} 
destacavam na "jurisprudência filosófica": (i) o próprio princípio da consciência de Reinhold, bem como (ii) a objeção de Schulze contra a cláusula de diferenciação entre objeto e representação. Assim, compreendemos que a contemplação das objeções dos céticos pode ser entendida como a adaptação do passo "3" do procedimento de formação de princípios e conceitos de um corpo doutrinário que vimos acima; a adaptação à matéria em questão - que é a consciência ${ }^{88}$ - nos permite conceber a comparação com "juízos corretos, apropriados ao assunto" com o que chamamos de "jurisprudência filosófica": as objeções dos céticos ao princípio de Reinhold. Lembrando ainda que os passos "1" e "2" compreendem, respectivamente, (1) uma análise das cognições, constatando a necessidade em separá-las por tipos (conhecimento intuitivo, discursivo ou abstrato, conhecimento matemático e geométrico e sentimentos ${ }^{89}$ ) e (2) o estabelecimento do que há de comum a essas cognições: são material para a justificação de juízos, supõem uma consciência, são representações, as quais podem formar uma cadeia complexa de relações necessárias, etc.

É preciso reiterar que nosso propósito no momento é mostrar que o procedimento de formação dos conceitos da filosofia de Schopenhauer pode ser entendido como influenciado pelo debate de recepção da filosofia crítica de Kant. Também é importante mencionar que a cláusula de identificação entre representação e objeto, que compõe o primeiro princípio de Schopenhauer será examinada sob outro prisma no prosseguimento que daremos a este trabalho; de modo que, nos parágrafos anteriores, nos concentramos em oferecermos uma interpretação do que teria sido o procedimento de formulação do primeiro princípio da filosofia de Schopenhauer, o princípio do $§ 16$ de PR.

Outro ponto do sistema de Schopenhauer no qual encontramos uma herança do projeto de Reinhold e reformulações que contemplam críticas de Schulze e Maimon é o estatuto da noção de faculdade cognitiva. Mostramos como a leitura de Schulze da noção de faculdade cognitiva da CRP, como comprometida com a hipostasiação do "eu penso", foi um modo de mostrar que Reinhold, com a sua teoria das faculdades em sua Elemntarphilosophie feria o espírito da CRP. Isso porque, como vimos, Reinhold era um famoso representante da recém criada filosofia crítica e compreendia a noção de faculdade cognitiva (Vorstellungsvermögen) como causa atuante da representação. Maimon, no seu comentário ao Änesidemus, afirmou, como vimos, que a filosofia crítica não precisava postular a

${ }^{88}$ SCHOPENHAUER, A. SW, II, 166: ”A filosofia ou metafísica enquanto doutrina da consciência (Lehre vom Bewusstsein)... ".

${ }^{89}$ Compare isso com a divisão das faculdades promovida por Schopenhauer. Coisa que examinamos no próximo capítulo e que voltamos a tocar na última seção do quaro capítulo, quando apresentamos a peculiaridade do conhecimento discursivo de ser a mediação de todos os tipos de representação através de juízos que utilizam conceitos de diferentes origens cognitivas. Que são, segundo Schopenhauer, quatro; daí: "raiz quádrupla do princípio de razão suficiente", nós podemos encontrar quatro maneiras diferentes de oferecer justificativas para juízos. 
existência de nenhuma entidade que fizesse as representações possíveis como causa da possibilidade ou da efetividade delas. A noção de faculdade cognitiva da CRP, de acordo com Maimon, é parasitária e não pode ser diferente do próprio conhecer; noção cuja função era apenas explicar as condições de possibilidade de que tenhamos representações. Ora, Schopenhauer terá uma teoria das faculdades que não se compromete com a existência de nenhuma entidade, mas com conceitos ou noções com funções meramente explicativas:

(...) elas [as faculdades cognitivas: sensibilidade, entendimento e razão] são expressões gerais para as classes de representações estabelecidas, que a cada época são mais ou menos precisamente diferenciadas naqueles poderes de conhecimento. Mas elas são abstraídas das representações, enquanto condição, em contra-partida ao necessário correlato daquelas representações, o sujeito; conseqüentemente, relacionam-se as classes de representações com faculdades cognitivas exatamente da mesma maneira que sujeito em geral com objeto em geral. Como imediatamente com o sujeito se coloca o objeto (do contrário a palavra seria sem significado) e da mesma maneira com o objeto, o sujeito; e, portanto: ser sujeito significa exatamente o mesmo que ter um objeto, assim como ser objeto significa ser conhecido por um sujeito. Exatamente da mesma maneira é o caso com um objeto de alguma maneira determinado: imediatamente coloca-se também o sujeito conhecendo da mesma maneira. Uma vez que é indiferente se eu digo: os objetos têm tais e tais determinações que a ele são inerentes e próprias; ou: o sujeito conhece de tal e tal maneira - é também indiferente se eu digo: os objetos se dividem em tais classes; ou: ao sujeito são peculiares tais e tais poderes de conhecimento. ${ }^{90}$ (sublinhado por mim)

Essa passagem nos revela que Schopenhauer tinha uma concepção de faculdade cognitiva muito mais próxima daquela rápida sugestão de Kant presente no prefácio da $1^{\mathrm{a}}$ edição da CRP e não sujeita às críticas de Schulze e Maimon à Elementarphilosophie de Reinhold, pois a sua noção de faculdade cognitiva não se compromete com nenhuma correspondência a qualquer tipo de entidade. A noção de faculdade cognitiva de Schopenhauer, desse modo, está de acordo com a filosofia crítica de Kant à medida que sua teoria das faculdades não realiza um discurso de primeira ordem sobre as faculdades cognitivas investigando a causa de um efeito - mas apenas tomando as faculdades cognitivas como condições de possibilidade de fazermos diferentes tipos de juízos, os quais supõem que tenhamos representações de naturezas distintas, ou diferentes formas de aplicação do princípio de razão suficiente. ${ }^{91}$ No entanto, como mencionamos acima, podemos encontrar o legado da Elementarphilosophie de Reinhold na teoria geral

\footnotetext{
${ }^{90}$ SCHOPENHAUER, A. SW, III, 169-70, PR: p. 209-10.

${ }^{91}$ Remeto o leitor ao $\$ 15$ de PR, passagem em que Schopenhauer analisa o que é necessário para responder à pergunta "por que um triângulo tem três lados e três ângulos que somam sempre $180^{\circ}$ ?". A resposta que damos a esta pergunta necessita que tenhamos um tipo peculiar de representação que não é nem espaço-temporal, nem puramente conceitual. Isso fará com que Schopenhauer estabeleça a relação entre razões ou justificativas para juízos (Erkenntnisgrund) e diferentes tipos de cognições; o poder que nos faculta responder àquela pergunta e a demais tipos de juízos é entendido como uma faculdade cognitiva.
} 


\section{ALEXANDRE TELES}

das faculdades de Schopenhauer: a noção de faculdade cognitiva é concebida a partir do princípio mais geral de conhecimento que determina as relações entre as noções de sujeito, objeto e representação. Mas é importante destacar que apesar de conceber a noção de faculdade cognitiva a partir da noção mais geral de conhecimento, tanto a noção mais geral de representação como a noção de faculdade cognitiva são abstrações $^{92}$, coisa que já destacamos acima e que faz parte da concepção metodológica de Schopenhauer de formação de um corpo doutrinário. Ora, abstração é a primeira coisa descartada por Reinhold na sua explicação de como o seu princípio da consciência (Satz des Bewusstseins) expressa o fato originário da consciência. $^{93}$

Essa diferença em relação à filosofia de Reinhold também pode ser vista como mais uma influência das críticas dos céticos ao projeto da Elementharphilosphie na edificação do sistema de Schopenhauer. Pois Schulze sugere que o princípio da consciência de Reinhold seja considerado um princípio sintético, gerado a partir de um processo de abstração ${ }^{94}$. Ora, Schopenhauer aceitará a segunda sugestão e recusará a primeira. Mas, considerando o fato de que os princípios mais gerais da filosofia de Schopenhauer são resultado abstrações - o que é resultado de uma exigência da própria teoria do conhecimento discursivo de Schopenhauer, que concebe os juízos todos como conexões entre conceitos e conceitos o resultado de um processo de abstração de representações mais completas - é uma questão pertinente se perguntar pela maneira com a qual se passa de um nível de abstração para o outro. Pois, o princípio do $§ 16$ de PRS que contém as relações entre sujeito e objeto, conhecedor e conhecido é a última abstração possível, isto é, contém as noções mais gerais de conhecimento - fato que já notamos em nota acima e também do que se depreende de passagens que citamos anteriormente nas quais o primeiro princípio da filosofia é descrito como o resultado de uma abstração que deve conter toda a multiplicidade do mundo e que é retomado na passagem acima citada -; já as noções de faculdade cognitiva e classe de objetos estão no nível imediatamente abaixo e são concebidas em consonância com o princípio que está no topo, no nível superior de abstração.

Ora, no $\S 1$ de PRS, Schopenhauer apresenta as leis metodológicas de homogeneidade e especificação. Elas é que regulamentam a passagem de um nível de abstração para o outro:

\footnotetext{
92 No parágrafo que antecedia essa última citação, afirmava Schopenhauer: “(...) a proposição eu conheço, que é para nós a última possível abstração (...)" SW, III, 169, PR:208, PR:§4.1.

93 REINHOLD, K.L., Beyträge zur Berichtigung bisheriger Meißverständnisse der Philosophen, p. 113, [168].

94 SCHULZE, G.E., Änesidemus oder über die Fundamente der von Herrn Professor Reinhold in Jena gelieferten Elementar-Philosophie, p. 62-3, [76-7].
} 
A lei de homogeneidade chama-se o apanhar as espécies através do prestar a atenção às semelhanças e acordo das coisas reunindo-as em classes e estas em gêneros até, em último lugar, chegarmos ao conceito mais geral que compreende tudo...

(...) A lei de especificação (...) exige que nós distingamos as espécies umas das outras sob um conceito genérico mais compreensivo e incluamos de novo a espécie mais genérica e a mais específica sob estas espécies ${ }^{95}$.

Essas leis metodológicas são apresentadas com apelo a Kant ${ }^{96}$ e Platão; coisa que deve ser entendida como a adoção de leis que fazem parte de um consenso cuja adoção está fora de disputa. Pois bem, tendo estabelecido o modo com o qual devemos conceber a relação entre o princípio do $§ 16$ de PRS, que contém as relações entre as noções de sujeito, objeto e representação, e as noções de faculdade cognitiva e classe de objetos, passemos a considerar a justificativa que Schopenhauer oferece para cada uma dessas relações. Tanto o princípio do $§ 16$ de PRS, como a teoria das faculdades de Schopenhauer, são princípios e esses, como todos os demais, são juízos, os quais, nada mais são do que uma conexão entre conceitos. Ora, a justificativa da conexão dos conceitos que compõem esses princípios é a própria justificativa desse princípios. Agora, como vimos, Schopenhauer considerava a relação entre sujeito e objeto uma relação recíproca - não há objeto sem sujeito e vice versa - e ainda: uma relação cuja negação é uma contradição. Isto é, o juízo do $§ 16$ de PRS é um juízo analítico. E, uma vez que a relação entre faculdades cognitivas e classe de objetos é concebida como um nível menos abstrato da relação vigente entre as noções de sujeito e objeto, contida no $§ 16$ de PRS, a relação entre faculdades cognitivas e classe de objetos da teoria das faculdades de Schopenhauer é, igualmente, uma relação cuja negação é uma contradição e que mantém aquela reciprocidade. Essa é a justificativa de Schopenhauer para sua teoria das faculdades: ela é resultado da aplicação da lei de especificação ao princípio mais geral de conhecimento. Isto é, a verdade metalógica ${ }^{97}$ ou analítica da teoria das faculdades de Schopenhauer, será utilizada para justificar as modificações que Schopenhauer promoveu na Doutrina dos Elementos da CRP ao conceber o seu sistema de filosofia transcendental da maneira que concebeu, depende de que se aceite a correção do princípio primeiro da filosofia de Schopenhauer, que, segundo nossa interpretação, foi confeccionado da maneira que acabamos de sugerir.

Cabe-nos fazer algumas considerações finais sobre como as semelhanças do projeto de Reinhold e de Schopenhauer se mantém, dadas as diferenças metodológicas que apresentamos. Em primeiro lugar, devemos levar em conta que o fato da consciência do qual Schopenhauer manifesta ter partido, como ${ }^{95}$ SCHOPENHAUER, A. SW, III, 11-2, PR: $§ 1$.

${ }^{96}$ Cf. CRP: B 684-686.

${ }^{97}$ Essa é uma aplicação do vocabulário da filosofia de Schopenhauer. $C f$. (PR: §33). 
conferimos em passagens acima, para não ser uma incoerência com o método de sua filosofia, precisa ser entendido como um fato interpretado e construído, de maneira semelhante como quando recorremos a um fato histórico, o qual só é um fato na medida em que homens os manipulam e moldam de alguma maneira. Pois, como vimos, a articulação das noções de sujeito, objeto e representação não é dada imediatamente como era no caso da filosofia de Reinhold, mas estabelecida através de processos de abstração e comparação com os quais esses conceitos fundamentais são gerados. Assim, o fato da consciência, no sistema de Schopenhauer, não é absolutamente primeiro, mas é estabelecido juntamente com a confecção do sistema. E ainda, os conceitos que compõem esse fato são todos eles construídos e não originários. Eles são conceitos concebidos de modo semelhante com o qual Kant concebia a construção de conceitos pela matemática que procedia por "construções de conceitos, originalmente arquitetados pela própria mente". Mas diferentes dessas no sentido em que apenas o instituem o significado de um termo, elas não serão, como as definições matemáticas, "produzidas sinteticamente" (A730/B758), demandando uma "apresentação a priori da intuição que corresponde ao conceito" (A713/B741). O procedimento de construção desse conceitos que compõem o primeiro princípio do sistema de filosofia transcendental de Schopenhauer demandam abstração e comparação com instâncias extra-judicativas - as próprias cognições enquanto tais - e, como sugerimos, jurisprudenciais.

\section{Referências}

SCHOPENHAUER, A. Sämtliche Werke. Pustet, Friederich, Stuttgart-Frankfurt am Main, Cotta-Insel Verlag, in fünf Bänden, 1960.

. Die Welt als Wille und Vorstellung I. In: . Sämtliche Werke - Band

I. Stuttgart-Frankfurt am Main: Cotta-Insel Verlag, 1960.

. Die Welt als Wille und Vorstellung II. In: . Sämtliche Werke - Band

II, Stuttgart-Frankfurt am Main, Cotta-Insel Verlag, 1960.

. Über die Vierfache Wurzel des Satzes vom Zureichenden Grunde. In: . Sämtliche Werke - Band III, p. 6-190. Stuttgart-Frankfurt am Main, Cotta-Insel Verlag,

1960.

. Parerga und Paralipomena I. In: . Sämtliche Werke - Band IV.

Stuttgart-Frankfurt am Main: Cotta-Insel Verlag, 1960. 
Revista Voluntas: Estudos sobre Schopenhauer - Vol. 3, Números 1 e 2 - $1^{\text {o e }} 2^{\text {o }}$ semestres de 2012 - ISSN: 2179-3786 - pp. 291-325.

. On the Fourfold Root of the Principle of Sufficient Reason (FR), La Salle: Open Court Press, Translator: PAYNE, E.F.J., 1974.

. The World as Will and Representation (in two volumes), New York: Dover Publications, Translator: PAYNE, E.F.J., 1969.

. O mundo como vontade e representação ${ }^{98}$, Rio de Janeiro: Contraponto Editora, Tradução: CORREIA, S. M. F., 2001. . O mundo como vontade e como representação. São Paulo: Editora UNESP, 2005.

KANT, I. Kant's Briefwechsel, Band II. Kant's gesammelte Schriften. Akademie-Ausgabe (Ak). Band XI. Berlin und Leipzig: Walter de Gruyter, 1922.

. Kritik der reinen Vernunft, 1781 (A), 1787 (B), In: Kant im Kontext - Werke auf CD-ROM, Karsten Worm - Info Software, 1996.

. Immanuel Kant's Critique of Pure Reason, St. Martin’s Press, Translation: SMITH, N.K., 1970.

. Crítica da Razão Pura, Lisboa: Fundação Calouste Gulbekian, Tradução: DOS SANTOS, M.P. \& MORUJÂO, A. F., 2001.

MAIMON, S. Versuch über die Transscendentalphilosophie mit einem Anhang über die symbolische Erkenntniß und Anmerkungen, Berlin, 1790.

. Versuch einer neuen Logik oder Theorie des Denkens: Nebst Angehängten Briefen des Philaletes an Änesidemus, Berlin, 1794.

REINHOLD, K. L. Beyträge zur Berichtigung bisheriger Meißverständnisse der Philosophen. Bd.I, Hamburg: Felix Meiner Verlag, 2003 [1790].

SCHULZE, G. E. Änesidemus oder über die Fundamente der von Herrn Professor Reinhold in Jena gelieferten Elementar-Philosophie, Hamburg: Felix Meiner Verlag, 1996 [1792].

AMERIKS, K. "On Being Neither Post- Nor Anti-Kantian", Inquiry: An Interdisciplinary Journal of Philosophy, 46 (2): 272-92, 2003.

. Cambridge Companion to German Idealism, Cambridge: Cambridge University Press,

2000.

. Introduction: Interpreting German Idealism, In: AMERIKS, K. Cambridge Companion to German Idealism, Cambridge: Cambridge University Press, p. 1-17, 2000.

\footnotetext{
${ }^{98}$ Edição incompleta: apenas o primeiro volume do original, sem prefácios nem o apêndice sobre a filosofia de Kant. Tendo em vista tal limitação da edição portuguesa, recomendamos a edição - completa - traduzida por BARBOZA, J . (2005).
} 
BECK, J.S. "Explanatory Abstract of the Critical Writing of Prof. Kant, Prepared with the Same, V. III which presents The Sandpoint from which Critical Philosophy is to be Judged", 1796. In: DI GIOVANNI, G. and HARRIS, H.S. Between Kant and Hegel: Texts in The Development of Post-Kantian Idealism, p. 204-50, Indianapolis, Hackett, 2000.

BEISER, F. The Fate of Reason: German Philosophy from Kant to Fichte. London: Harvard Press, 1987.

BONACCINI, J.A. Kant e o Problema da Coisa em Si no Idealismo Alemão, Rio de Janeiro: Editora Relume Dumará, 2003.

BREAZEALE, D. Two Cheers for Post-Kantianism, Inquiry: An Interdisciplinary Journal of Philosophy, 46 (2): 239-59, 2003.

CASSIRER, E. Das Erkenntnisproblem in der Philosophie und Wissenschaft der Neuren Zeit, Band III: Die Nachkantischen Systeme, Hildesheim: Georg Olms Verlag, 1974. (1923)

DI GIOVANNI, G. and HARRIS, H.S. Between Kant and Hegel: Texts in The Development of Post-Kantian Idealism, p. 2-50, Indianapolis, Hackett, 2000a.

. The Facts of The Consciousness, In: DI GIOVANNI, G. and HARRIS, H.S. Between Kant and Hegel: Texts in The Development of Post-Kantian Idealism, p. 2-50, Indianapolis, Hackett, $2000 \mathrm{~b}$.

GOODMAN, N. Fact, Fiction and Forecast, Massachusetts: Harvard University Press, 1979.

HARTMANN, N. A Filosofia do Idealismo Alemão, Fundação Calouste Gulbekian, Tradução: BELO, J. G. , 1960.

HENRICH, D. "The Proof-Structure of Kant's Transcendental Deduction”, Review of Metaphysics, 22:4, p.640-59, 1969.

. Kant's Notion of a Deduction, In: Kant's Transcendental Deductions, Stanford: Stanford University Press, p.30-46, 1989.

HOYOS, L.E. El Escepticismo y la Filosofía Transcendental: Estudios sobre el pensamiento alemán a fines del siglo XVIII, Bogotá, Siglo del Hombres Editores, 2001a.

TELES, A. "Um Ensaio sobre a crítica de Schopenhauer à Doutrina das Categorias de Kant", Barbarói, n.26, pp.133-159, 2007.

. O Sistema de Filosofia Transcendental de Schopenhauer: Uma Interpretação e Defesa. Porto $\overline{\text { Alegre, } 230}$ p. (Dissertação de Mestrado), UFRGS, 2009.

Recebido: $26 / 10 / 12$

Received: $10 / 26 / 12$

Aprovado: 21/12/12 
Revista Voluntas: Estudos sobre Schopenhauer - Vol. 3, Números 1 e 2 - $1^{\text {o e }} 2^{\text {o }}$ semestres de 2012 - ISSN: 2179-3786 - pp. $291-325$.

Approved: 12/21/12 